\title{
RESPONSABILIDAD POR NACIMIENTO EVITABLE (WRONGFUL BIRTH) Y DISCAPACIDAD'
}

\author{
VÍCTOR TORRE DE SILVA LÓPEZ DE LETONA \\ IE Law School \\ victor.torre@ie.edu
}

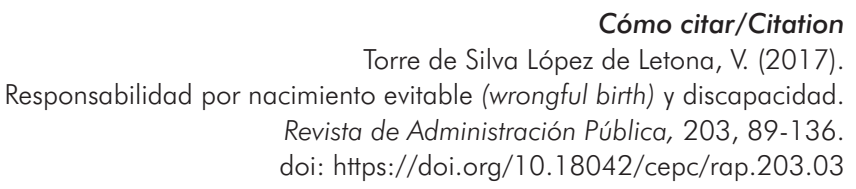

Resumen

La responsabilidad por wrongful birth, tanto patrimonial de la Administración como civil extracontractual, constituye un fenómeno relativamente reciente, que tiene sus orígenes en Estados Unidos. Sobre la base de diversas sentencias de las Salas Primera y Tercera del Tribunal Supremo, la doctrina ha ido perfilando sus elementos, no exentos de polémica. Sin embargo, aún no se ha proyectado sobre este tipo de responsabilidad la Convención sobre los Derechos de las Personas con Discapacidad, adoptada por la Asamblea General de las Naciones Unidas el 13 de diciembre de 2006, ratificada por Espańa, que introduce una nueva perspectiva. A su luz resulta pertinente replantear cuestiones fundamentales de este tipo de responsabilidad.

\section{Palabras clave}

Responsabilidad patrimonial de la Administración; responsabilidad en materia sanitaria; discapacidad; wrongful birth.

1 Quiero agradecer a los profesores de IE Law School Francisco Marcos Fernández y Fernando Pastor Marchante sus observaciones sobre este trabajo. 


\section{Abstract}

Wrongful birth torts appeared first in the United States of America and have recently been imported to Spain. They may involve governmental officials, when arise in the context of governmental healthcare. Spanish authors have studied them, not infrequently controversial, taking on account some judgments of the Spanish Supreme Court, both from the Civil Law Chamber and from the Administrative Law Chamber. However, the Convention on the Rights of Persons with Disabilities, adopted by the United Nations General Assembly on 13 December 2006, ratified by Spain, adds a new perspective on wrongful birth torts. Their basic tenets should be reviewed according to this international Convention.

\section{Keywords}

Torts; persons with disabilities; medical malpractice; State liability; wrongful birth. 


\section{SUMARIO}

I. ALGUNAS PRECISIONES INTRODUCTORIAS. II. ELEMENTOS DE LA RESPONSABILIDAD POR WRONGFUL BIRTH: EL DAÑO Y LA RELACIÓN DE CAUSALIDAD: 1. El daño. 2. La relación de causalidad. III. LA LEX ARTIS AD HOC EN LA JURISPRUDENCIA CIVIL Y CONTENCIOSO-ADMINISTRATIVA. IV. LA CONVENCIÓN SOBRE LA PROTECCIÓN DE LAS PERSONAS CON DISCAPACIDAD.

\section{ALGUNAS PRECISIONES INTRODUCTORIAS}

El derecho de daños ha tenido un crecimiento notable desde la codificación. Díez-Picazo citaba distintas vías para explicar este fenómeno, como la pérdida de excepcionalidad de la responsabilidad por omisión, la aparición del daño moral o el surgimiento de la doctrina del riesgo ${ }^{2}$. Tal vez otros factores sociales también hayan coadyuvado a ese crecimiento, por ejemplo la revolución industrial ${ }^{3}$ (en su doble faceta de responsabilidad por nuevas máquinas, típicamente el ferrocarril, y de responsabilidad por accidentes laborales) o incluso el nacimiento y desarrollo del llamado Estado de bienestar, que extiende la idea de la cobertura general de riesgos asociados a la vida. A lo largo de este período se ha dejado sentir también una influencia del Common Law, que quizá ha coadyuvado a una mayor extensión de la responsabilidad extracontractual.

Uno de los campos que ha crecido en las últimas décadas es la responsabilidad de los profesionales sanitarios ${ }^{4}$. Desde un plano civil, abarca tanto

2 L. Díez-Picazo y Ponce de León (2000), Derecho de daños, Madrid: Civitas (págs. 93, 95 y 108).

3 A. Macía Morillo (2007), «La responsabilidad civil médica. Las llamadas acciones de wrongful birth y wrongful life», Revista de Derecho, 27, págs. 3-37 (pág. 6).

4 Hace algo más de dos décadas, Santiago Muñoz Machado (1994) indicaba: «No conozco ninguna estadística que mida la cantidad y la frecuencia de las acciones y con- 
responsabilidad contractual como extracontractual ${ }^{5}$. En países como España, en los que existe una fuerte presencia pública en el campo de la sanidad, esto se ha trasladado a la Administración en forma de reclamaciones de daños y perjuicios, hoy en día configuradas como de responsabilidad patrimonial. Han experimentado un crecimiento espectacular en los últimos tiempos ${ }^{6}$, de

denas por responsabilidad de los médicos. Pero, desde luego, su multiplicación la percibimos los juristas con sólo atenernos a la humilde práctica de repasar los repertorios de jurisprudencia de los últimos años. El número de sentencias producidas en todos los órdenes jurisdiccionales que enjuician problemas de mala práctica sanitaria se ha multiplicado, en efecto. Dicha progresión no es manifiesta sólo en España. Es un fenómeno universal en los países con servicios sanitarios desarrollados», "Responsabilidad de los médicos y responsabilidad de la Administración sanitaria», Documentación Administrativa, 237-238, págs. 255-281 (págs. 255-256).

5 Sobre esta dualidad (responsabilidad contractual o extracontractual), véase A. Macía Morillo Morillo (2005), La responsabilidad médica por los diagnósticos preconceptivos y prenatales (las llamadas acciones de wrongful birth y wrongful life), Valencia: Tirant lo Blanch, págs. 145-207. La jurisprudencia civil no saca consecuencias relevantes de esta distinción, lo que critican M. Martín Casals y J. Solé Feliu (2002), "Comentario a la sentencia del Tribunal Supremo de 7 de junio de 2002", Cuadernos Civitas de Jurisprudencia Civil, 60, marginal 1627, págs. 1097-1121 (pág. 1106): «Debe reconocerse que nuestra práctica jurisprudencial convierte en irrelevante el problema, porque conforme a la llamada doctrina de la "unidad de culpa civil" la "yuxtaposición de las responsabilidades contractuales y extracontractuales [...] da lugar a acciones que pueden ejercitarse alternativa o subsidiariamente u optando por una u otra e incluso proporcionando los hechos al juzgador para que éste aplique las normas de concurso de ambas responsabilidades que más se acomoden a ellos, todo a favor de la víctima y para el logro de un resarcimiento lo más completo posible"».

6 En palabras de Juan Pemán Gavín (1994): «La materia sanitaria ha venido a sumarse en nuestro país en los últimos años a otros ámbitos de la actividad pública en los que resulta frecuente la litigiosidad y, concretamente, el ejercicio de pretensiones resarcitorias. Ello resulta en efecto una novedad, pues hasta hace relativamente pocos ańos era muy infrecuente el ejercicio de acciones de responsabilidad en relación con la actividad médica o sanitaria en general, y en particular en relación con la actividad sanitaria realizada en centros asistenciales de titularidad pública», «La responsabilidad patrimonial de la Administración en el ámbito sanitario público», Documentación Administrativa, 237-238, págs. 283-331 (págs. 283-284). Resulta significativo que este mismo autor, diez ańos antes, en 1984, indicaba que «los supuestos de responsabilidad decididos por los tribunales en materia sanitaria han sido muy poco numerosos» y que "todavía más escasos son los supuestos resueltos de modo favorable para el paciente», pues «las posibilidades que encierra en esta materia la cláusula de responsabilidad patrimonial de la Administración [...] están aún por descubrir», con lo que pronosticaba 
suerte que en la actualidad es el principal foco de litigiosidad en materia de responsabilidad patrimonial, con un $41,8 \%$ de todos los recursos contencioso-administrativos de este ámbito ${ }^{7}$.

De hecho, la considerable extensión de la responsabilidad patrimonial de la Administración en materia sanitaria fue escogida como campo para elevar agudas críticas sobre la institución en general, en relación con la responsabilidad civil análoga, por parte de Pantaleón ${ }^{8}$.

«un aumento de los casos», Pemán Gavín (1984), «Hacia un estatuto del enfermo hospitalizado", Revista de Administración Pública, 103, págs. 89-140 (págs. 137-138). En el mismo sentido, M. Cueto Pérez (2009), «Responsabilidad patrimonial de la Administración en el ámbito sanitario», en T. Quintana López (dir.), La responsabilidad patrimonial de la Administración pública, Valencia: Tirant lo Blanch, tomo II, págs. 837-884 (pág. 837), y J. Guerrero Zaplana (2002), «Las peculiaridades de la responsabilidad patrimonial de la Administración sanitaria: el criterio de la lex artis», en J. Guerrero Zaplana (dir.), La responsabilidad patrimonial de la Administración sanitaria, Cuadernos de Derecho Judicial I-2002, Consejo General del Poder Judicial, págs. 53-105 (pág. 57). En esta línea, en el ámbito civil, Macía destaca que «en los últimos años, estos profesionales [los sanitarios] se han visto sometidos progresivamente a un —llamémoslo así- acoso, desconocido hasta hace relativamente poco» (2007, «La responsabilidad civil médica...»: 12): igualmente en A. Macía Morillo (2007), «Una visión general de las acciones de responsabilidad por wrongful birth y wrongful life y de su tratamiento en nuestro ordenamiento jurídico", Anuario de la Facultad de Derecho de la Universidad Autónoma de Madrid, 10, págs. 65-93 (pág. 73).

7 F. Pastor Merchante (2016), «Análisis de la litigiosidad administrativa y contenciosoadministrativa en materia de responsabilidad patrimonial», en S. Díez Sastre (dir.), Informe sobre la Justicia Administrativa 2016, Centro de Investigación sobre Justicia Administrativa de la Universidad Autónoma de Madrid, págs. 179-216 (pág. 188). Además, este autor indica que de los dictámenes en materia de responsabilidad patrimonial de los Consejos Consultivos autonómicos considerados (Aragón, Castilla y León, Baleares, Extremadura y Madrid), el porcentaje más numeroso se refiere a materia sanitaria, con un $29 \%$ (pág. 184).

8 F. Pantaleón Prieto (1994), «Los anteojos del civilista. Hacia una revisión del régimen de responsabilidad patrimonial de las Administraciones públicas», Documentación Administrativa, 237-238, págs. 239-253. Tomaba pie en la Sentencia del Tribunal Supremo (Sala 3a) de 14 de junio de 1991, ponente José María Reyes Monterreal. Este trabajo luego fue recogido en el libro de F. Pantaleón Prieto (1995), Responsabilidad médica y responsabilidad de la Administración, Madrid: Civitas, págs. 63-91. Continuó con su punto de vista algunos años después en F. Pantaleón Prieto (2000), «Cómo repensar la responsabilidad civil extracontractual (también de las Administraciones públicas)», en J. A. Moreno Martínez (coord.), Perfiles de la responsabilidad civil en el nuevo milenio, Madrid: Dykinson, págs. 437-465. 
Como se aprecia, la responsabilidad en materia sanitaria es un «territorio fronterizo» entre el derecho civil y el administrativo, con jurisprudencia en ambos órdenes jurisdiccionales. El mismo tipo de suceso, en efecto, se analiza desde el punto de vista civil y se residencia ante tribunales civiles en caso de que no haya tenido parte la Administración o, en caso contrario, el análisis sustantivo pasa a ser de derecho administrativo, con competencia de la jurisdicción contencioso-administrativa' ${ }^{9}$. Hay una confluencia evidente entre ambas aproximaciones, aunque también algunas diferencias notables, que no es el momento de analizar con carácter general. Ciertamente, este carácter «fronterizo» le da un atractivo especial, aunque también complica algo su estudio.

En las páginas que siguen se abordará un supuesto peculiar de responsabilidad sanitaria: la llamada responsabilidad por wrongful birth. Se trata de un supuesto relativamente reciente, no exento de polémica ${ }^{10}$. Sin embargo, no se persigue hacer una exposición general de este tipo de responsabilidad, sino introducir en ella una perspectiva que hasta la fecha no ha sido tenida en cuenta en el debate: la Convención sobre los Derechos de las Personas con

9 Ciertamente, si los servicios sanitarios que han causado la lesión son privados, pero forman parte de un mecanismo de prestación de los servicios públicos (por ejemplo, concierto con la Administración o contrato de gestión de servicios públicos), cabe acudir al procedimiento administrativo para solicitar de la Administración la indemnización y, en caso de no satisfacerse la pretensión, ante la jurisdicción contenciosoadministrativa. Así lo defiende con toda corrección M. Cueto Pérez (2016), «Incidencia de las Leyes 39 y 40/2015 en la responsabilidad patrimonial por asistencia sanitaria en supuestos de gestión privada», Revista de Administración Pública, 201, págs. 303-333. Argumenta que la derogación de la Ley 30/1992, de 26 de noviembre, de Régimen Jurídico de las Administraciones Públicas y del Procedimiento Administrativo Común, cuya disposición adicional duodécima no se recoge en la nueva legislación, no cambia esta conclusión.

10 La polémica es ampliamente reconocida: A. Mondaca Miranda, C. Aedo Barrena y L. Coleman Vega (2015), «Panorama comparado del wrongful life, wrongful birth y wrongful conception. Su posible aplicación en el Derecho chileno», Revista Ius et Praxis, 1, págs. 19-56; A. Vicandi Martínez (2013), «El concepto de wrongful birth y su inherente problemática», Revista de Derecho, Empresa y Sociedad, 3, págs. 40-59; M. N. Pacheco-Jiménez (2011), "Acciones de wrongful birth y wrongful life: una controvertida vía de responsabilidad civil médica», Documento de trabajo 2011/2 del Seminario Permanente de Ciencias Sociales de la Universidad de Castilla-La Mancha, págs. 3-16 (pág. 11); L. Elizari Urtasun (2010), «El daño en las acciones de wrongful birth y wrongful life», Derecho y Salud, vol. 19, págs. 139-163; T. J. Aliste Santos (2007), «El favor nascituri y su aplicación por el juez ante las demandas de wrongful life y wrongful birth», Práctica de Derecho de Daños, 49, págs. 5-17. 
Discapacidad, celebrada en Nueva York el 13 de diciembre de 2006 y ratificada por Espańa mediante instrumento de 23 de noviembre de 2007. Esta perspectiva resulta de interés, a mi juicio, tanto para la responsabilidad civil como para la responsabilidad patrimonial de la Administración.

Con carácter preliminar, parece necesario delimitar conceptos. Como señala Macía, fue en los Estados Unidos donde nació la responsabilidad por wrongful birth y por wrongful life, como formas del tort of negligence y desde allí se extendió a otros países como Inglaterra, Francia, Alemania y España ${ }^{11}$. Sin embargo, hoy en día se excluyen ambas formas en no pocos Estados de los Estados Unidos, por intervenciones de legislador ${ }^{12}$. A su alrededor han crecido supuestos más o menos cercanos, como la responsabilidad por wrongful conception o por wrongful death, que conviene deslindar. El uso de la terminología inglesa se justifica, como dice Macía, porque son expresiones técnicas ampliamente aceptadas y por la dificultad de encontrar términos en español que reúnan la misma carga significativa ${ }^{13}$.

En las acciones por wrongful death, un nińo muere en el parto o al poco de éste, en relación con una actuación u omisión sanitaria. La peculiaridad, respecto de un supuesto ordinario de responsabilidad médica, consiste en que quienes reclaman no son los padres por el daño moral de la muerte, sino que lo hacen en nombre del difunto ${ }^{14}$. No se admite en el Reino Unido, aunque sí en algunos casos en los Estados Unidos ${ }^{15}$. En España sería inviable, pues si no llega a nacer vivo carecería de personalidad jurídica (arts. 29 y 30 del Código

11 Macía Morillo (2005: 118; 2007, «La responsabilidad civil médica...»: 7-9; 2007, «Una visión general...»: 67, nota 8, y 68). Los primeros asuntos fallados en los Estados Unidos se describen en R. de Ángel Yágüez (1996), "Diagnósticos genéticos prenatales y responsabilidad (parte I)», Revista de Derecho y Genoma Humano, 4, págs. 105-117 (págs. 111-117): el primer caso estimatorio de wrongful birth fue la sentencia de la Corte Suprema de Texas de 19 de febrero de 1975, asunto Jacobs $v$. Theimer. También Mondaca, Aedo y Coleman (2015: 22-26).

12 Están excluidas ambas formas en Dakota del Sur, Idaho, Indiana, Michigan, Minnesota, Missouri, Pennsylvania y Utah: A. Ruda (2010), «I didn't Ask to be Born: Wrongful Life from a Comparative Perspective», Journal of European Tort Law, vol. 1, 2, págs. 204-241 (pág. 206).

13 Macía Morillo (2005: 52). En el mismo sentido, Ángel Yágüez (1996, I: pág. 107, en nota 5). Por su parte, Salàs sugiere utilizar los términos «nacimiento evitable» por wrongful birth y «eugenesia fallida» por wrongful life: J. T. Salàs Darrocha (2005), "Las acciones de wrongful birth y wrongful life ante la Jurisdicción ContenciosoAdministrativa», Actualidad Administrativa, 22, págs. 2692-2711 (pág. 2692).

14 Macía Morillo (2005: 50, en nota 46).

15 Ibid. 
Civil), con lo que no habría representación ni sucesión «mortis causa». Si nace vivo se entiende que el derecho al resarcimiento por la muerte solo surge tras ella, con lo que al no considerarse un derecho del causante (de los que no se extinguen por su muerte) no integra la herencia (art. 659 del Código Civil), ni los herederos en su condición de tales pueden reclamar indemnización: solo cabe que reclamen los familiares por derecho propio ${ }^{16}$.

El punto común de las otras tres formas (wrongful birth, wrongful life y wrongful conception) consiste en que el hecho que desencadena la responsabilidad es el nacimiento de un niño. Aun hay otro punto compartido: si el nacido está afectado por una patología o discapacidad, los servicios sanitarios no deben haber tenido ninguna participación, ni activa ni omisiva, en su surgimiento ni en su agravamiento ${ }^{17}$. En consecuencia, quedan fuera de los tres tipos de responsabilidad aquellos casos en los que, habiendo nacido un nińo aquejado de una patología, se omitió un tratamiento o terapia que hubiera podido curarla o aliviarla. También quedan fuera los supuestos en que la patología ha sido de algún modo provocada por una intervención de los servicios sanitarios (antes del parto o en el parto), sea del tipo que sea (farmacológica, quirúrgica, obstétrica, etcétera).

Las tres formas tienen diferencias entre sí. En los dos primeros casos (wrongful birth o wrongful life), la madre desea el embarazo, o al menos tácitamente lo acepta, y luego nace un nińo afectado por una patología, generalmente grave. La más común es el síndrome de Down ${ }^{18}$. En la wrongful conception (en ocasiones denominada wrongful pregnancy ${ }^{19}$ ), en cambio, el embarazo

16 F. Castro Bravo (1976), Temas de Derecho Civil, Madrid: Rivadeneyra, págs. 11-13; M. E. Rovira Sueiro, «La responsabilidad civil por daños a los derechos de la personalidad», en J. M. Pena López (dir.) (2004), Derecho de la responsabilidad civil extracontractual, Barcelona: Cálamo, págs. 299-324, págs. 302-305); M. Medina Crespo (2000), «Los principios que inspiran la regulación de las indemnizaciones básicas por causa de muerte, en el sistema de la Ley 30/95», en Moreno Martínez (coord.) (2000: 377-395, págs. 382-383). Es algo comúnmente admitido hoy en día, con amplia jurisprudencia.

17 Esto es aceptado comúnmente. Por ejemplo, J. C. Galán Cortés (2016), Responsabilidad civil médica, Cizur Menor: Civitas, Thomson-Reuters, 5ª ed., pág. 565, en nota 80 .

18 Elizari subrayaba en el año 2010 que de las 21 sentencias dictadas hasta el momento por el Tribunal Supremo en los dos órdenes jurisdiccionales (12 por la Sala de lo Civil y 9 por la de lo Contencioso-Administrativo), 10 correspondían a nacimientos con síndrome de Down (7 de la Sala de lo Civil y 3 de la Sala de lo Contencioso-Administrativo) (2010: 140, en nota 3).

19 Macía Morillo (2005: 51, en nota 49); Ángel Yágüez (1996, parte I: 107). 
es excluido por la madre, de modo que se usa alguna técnica anticonceptiva o de esterilización, que, sin embargo, no impide la concepción y ulterior nacimiento. En estos supuestos el nacido no tiene por qué sufrir patología alguna. Se trata de una responsabilidad por fallo del método anticonceptivo o de la esterilización, de la que no se tratará en estas páginas.

Los presupuestos de la responsabilidad por wrongful birth y por wrongful life son los siguientes, de acuerdo con Macía ${ }^{20}$ :

1. Las enfermedades o defectos ${ }^{21}$ graves del embrión o feto no podían ser curados, de acuerdo con la ciencia médica, aunque hubiesen sido diagnosticados a tiempo.

2. Sí existían técnicas y conocimientos suficientes en el lugar y en el momento para hacer un diagnóstico de ellos, de acuerdo con la lex artis ad hoc.

3. En el ordenamiento jurídico de aplicación a los hechos se prevé la facultad de la interrupción voluntaria del embarazo para tales diagnósticos ${ }^{22}$.

Sin embargo, ambas responsabilidades se distinguen por el sujeto activo. En la responsabilidad por wrongful birth es típicamente la madre (aunque en ciertos casos puede ser también el padre, como se verá), en todo caso uno o los dos progenitores ${ }^{23}$. En la responsabilidad por wrongful life el sujeto

20 A. Macía Morillo (2011), «El tratamiento de las acciones de wrongful birth y wrongful life a la luz de la nueva ley sobre interrupción voluntaria del embarazo», Revista Jurídica de la Universidad Autónoma de Madrid, 23, págs. 83-98. También, A. Macía Morillo (2009), «Panorama de la responsabilidad civil de los profesionales sanitarios por wrongful birth y wrongful life», Revista Chilena de Derecho Privado, 12, págs. 167-206 (págs. 172-177). Esta misma autora señala que cabe que el diagnóstico erróneo no sea solo prenatal, sino también anterior a la concepción, en caso de padres que sospechan que son portadores de una enfermedad congénita: Macía Morillo (2005: 257-258; 2007, «La responsabilidad civil médica...»: 15; 2007, «Una visión general...»: 76).

21 Respeto estas palabras, que usa Macía, aunque sería mejor emplear otras con menor carga semántica.

22 Esto último es ampliamente reconocido: Martín Casals y Solé Feliú (2002: 1110), M. Martín Casals y J. Solé Feliú (2007), "Comentario a la sentencia del Tribunal Supremo de 18 de mayo de 2006», Cuadernos Civitas de Jurisprudencia Civil, 73, marginal 1966, págs. 517-542 (pág. 529); Galán Cortés (2016: 570). Por eso en ordenamientos como el chileno en el que el aborto no está permitido no se aplica tal responsabilidad: Mondaca Miranda, Aedo Barrena y Coleman Vega (2015: 30-31). Como elemento de contraste, Vicandi Martínez lo pone en duda (2013: 54, en nota 44 y 57), como una hipótesis teórica.

23 Pero el padre solo no puede pretender esta responsabilidad, pues la facultad de interrumpir el embarazo, quicio sobre el que gira el supuesto de wrongful birth, compete 
activo es el nacido, por lo común representado por sus padres o tutores ${ }^{24}$. Resulta generalmente admitido que en Espańa no se indemniza la responsabilidad por wrongful life ${ }^{25}$, al igual que ocurre dentro de Europa, en Francia

en exclusiva a la madre. Por eso las acciones interpuestas solo por el padre se desestiman, como en la de la sentencia del Tribunal Superior de Justicia de Asturias que fue confirmada por la del Tribunal Supremo (Sala 3a) de 5 de diciembre de 2007, recurso 92/2007, ponente Agustín Puente Prieto.

24 Ángel Yágüez (1996, parte I: 109-110). Macía (2007, «Una visión general...»: 82, en nota 55). Aunque las lesiones del nacido no determinen su incapacidad, como el cómputo del dies a quo para comenzar la prescripción de la responsabilidad no se dilata hasta su mayoría de edad, sino que sigue el criterio de la actio nata (art. 1969 del Código Civil) o el de la determinación del alcance de las secuelas (art. 67.1 de la Ley 39/2015, de 1 de octubre, del Procedimiento Administrativo Común de las Administraciones Públicas), la acción interpuesta directamente por el nacido al cumplir dieciocho años estaría prescrita.

25 Macía Morillo (2005: 580-583; 2007, «La responsabilidad civil médica...»: 24-29); A. Macía Morillo (2008), «Negligencia médica en el seguimiento del embarazo y responsabilidad por wrongful birth. Comentario a la STS (Sala 1a) de 24 de octubre de 2008", Revista Jurídica de la Universidad Autónoma de Madrid, 18, 2008-II, págs. 189-210 (págs. 196, en nota 4, y 197); Martín Casals y Solé Feliú (2002: 1120-1121; 2007: 540); Elizari (2010: 158). Y ello pese a alguna sentencia de tribunal inferior que la impone, como la del Juzgado de Primera Instancia en el asunto que finalizó por la Sentencia del Tribunal Supremo (Sala 1a) de 18 de mayo de 2006, recurso 3337/1999, ponente José Antonio Seijas Quintana, que no fue corregida por vía de recurso ni por la Audiencia Provincial de Barcelona ni por el Tribunal Supremo. Véase el comentario crítico de Martín Casals y Solé Feliú (2007: 540-542). Lo mismo ocurrió con la sentencia del Juzgado de Primera Instancia en el asunto que concluyó por Sentencia del Tribunal Supremo de 18 de diciembre de 2003, recurso 766/1998, ponente Jesús Corbal Fernández, si bien en este caso la Audiencia Provincial dictó sentencia absolutoria, que fue casada. En cambio, en la sentencia de la misma Sala 1a, de 6 de julio de 2007, recurso 3036/2000, ponente José Antonio Seijas Quintana, se excluyó la indemnización para el hijo enfermo (wrongful life) que se había dado en instancia. Tampoco se admitió este tipo de responsabilidad en la sentencia de la Sala $1^{\text {a }}$ del Tribunal Supremo de 23 de noviembre de 2007, recurso 4469/2000, ponente Encarnación Roca Trías, ni en la sentencia de la Sala $3^{\text {a }}$ del mismo Tribunal de 4 de noviembre de 2008, recurso 4936/2004, ponente Luis María Díez-Picazo Giménez. En cambio, de modo aislado, Ángel Yágüez se muestra abierto a una indemnización limitada en casos de wrongful life, R. de Ángel Yágüez (2002), «La tercera sentencia del Tribunal Supremo sobre casos de wrongful birth. Mi intento de conciliar su doctrina con la de las dos sentencias anteriores", Revista de Derecho y Genoma Humano, 17, págs. 179-202 (págs. 190-191). 
hoy en día ${ }^{26}$, en Italia ${ }^{27}$, en Alemania ${ }^{28}$, en el Reino Unido ${ }^{29}$, en Austria ${ }^{30}$, en Dinamarca ${ }^{31}$, en Grecia $^{32}$, en Hungría ${ }^{33}$, en Portugal ${ }^{34}$ y en Bélgica ${ }^{35}$ en

26 En Francia hubo un primer caso estimatorio de wrongful life, pues la Corte de Casación concedió una indemnización a la familia Perruche (arrêt de 17 de noviembre de 2000), en una acción interpuesta por los padres en nombre de su hijo, el cual había nacido con afecciones neurológicas, sensoriales y cardiológicas graves y definitivas a consecuencia de la rubeola de la madre: esta tenía unos síntomas ya en su embarazo y comunicó al médico su voluntad de abortar de confirmarse tal enfermedad, que en un análisis serológico erróneo se excluyó. Esta sentencia dio lugar primero a tres sentencias contrarias de la Corte de Casación en casos similares (todas de 13 de julio de 2001), pero luego retomó la doctrina «Perruche» e indemnizó al hijo en dos nuevas sentencias de 28 de noviembre de 2001. A todo esto puso fin la Ley 2002-303, de 4 de marzo de 2002, que eliminó la responsabilidad por wrongful life: Martín Casals y Solé Feliu (2002: 1118-1119; 2007: 537-538); Macía (2007, «La responsabilidad civil médica...»: 29-32; 2007, "Una visión general...»: 90-91, nota 81); J. R. de Verda y Beamonte y P. Chaparro Matamoros (2012), «Responsabilidad civil médica en relación con el nacimiento de un ser humano", en J. R. de Verda y Beamonte (coord.), Responsabilidad civil en el ámbito de las relaciones familiares, Cizur Menor: Thomson Reuters-Aranzadi, págs. 23-49 (págs. 2429); y Mondaca Miranda, Aedo Barrena y Coleman Vega (2015: 25-26). Su aplicación retroactiva dio lugar a una condena a Francia, únicamente por la retroactividad, por violación del derecho de propiedad (art. 1 del Protocolo 1), por parte del Tribunal Europeo de Derechos Humanos, en el asunto Draon contra Francia, Sentencia de 6 de octubre de 2005, caso 1513/03. Hoy en día la ley está recogida en el art. L 114-5 del «Code de l'action sociale et des familles».

27 La Sentencia de la Corte Suprema de Casación de 29 de julio de 2004 negó legitimación activa a un menor para ejercitar la acción de wrongful life, al entender que no existía un derecho a nacer sano (Galán Cortés, 2016: 566). Es de notar que, como más tarde se indicará, en Italia no hay un supuesto específico de aborto por patologías del feto (Galán Cortés, 2016: 575).

Martín Casals y Solé Feliu (2007: 536-537), Ruda (2010: 205), que apunta que el aborto por malformaciones del feto no se permite a partir de 1995 (2010: 208).

29 Martín Casals y Solé Feliu (2007: 537). Ruda (2010: 206) indica que esa responsabilidad se excluye por la Congenital Disabilities Civil Liability Act de 1976.

30 Ruda (2010: 205).

31 Id.

$32 \mathrm{Id}$.

$33 I d$.

34 Id.

35 Id. El caso de Bélgica es interesante y paralelo a Francia, pues algunas sentencias favorables dieron lugar a la Ley de 15 de mayo de 2007, relativa a la compensación por daños derivados de atención médica, que lo prohibió. 
ninguna de sus versiones: ni contra los padres por haberle concebido ${ }^{36} \mathrm{ni}$ contra el médico o la Administración sanitaria ${ }^{37}$. Por este motivo, en las páginas que siguen no se tratará de este tipo de responsabilidad: el estudio se ceñirá, exclusivamente, a la responsabilidad por wrongful birth.

\section{ELEMENTOS DE LA RESPONSABILIDAD POR WRONGFUL BIRTH: EL DAÑO Y LA RELACIÓN DE CAUSALIDAD}

No es propósito de este trabajo hacer un análisis profundo de los distintos elementos de la responsabilidad por wrongful birth, sino examinar el impacto que sobre ella tiene, o debería tener, la Convención sobre los Derechos de las Personas con Discapacidad adoptada por la Asamblea General de las Naciones Unidas el 13 de diciembre de 2006, que se trata en un epígrafe posterior. Por tanto, ni se abordarán las cuestiones que se plantean con exhaustividad ni tampoco se ofrecerá una opinión sobre muchos de sus aspectos. Sin embargo, una introducción sobre el daño y la relación de causalidad parece imprescindible, pues de otro modo no se comprendería bien el alcance de la responsabilidad por wrongful birth o sus perfiles principales.

36 Como hacen notar Macía Morillo (2005: 66-67) y Galán Cortés (2016: 565, en nota 82), podría también fundarse en alguna actividad de riesgo asumida por la madre en gestación que hubiese desencadenado un daño. Este mismo autor explica que el aborto jamás puede ser considerado como un deber, de suerte que el no practicarlo comporte la causación de un daño antijurídico al hijo (pág. 566).

37 La responsabilidad por wrongful life no es aceptada en la mayoría de los sistemas jurídicos europeos, salvo en Holanda: Martín Casals y Solé Feliú (2007: 538-540), Galán Cortés (2016: 571, en nota 94). Ruda (2010: 206) apunta que solo tres estados de los Estados Unidos la reconocen (California, New Jersey y Washington) y que no se admite en países como Canadá, Australia y Sudáfrica (2010: 205-206 y 210). Esto es confirmado respecto de Sudáfrica por S. Human y L. Mills (2010), «The Immeasurable Wrongfulness of Being: The Denial of the Claim for Wrongful Life», Stellenbosch Law Review, 21, 1, págs. 67-89. Macía menciona los tres estados de Estados Unidos citados y añade Colorado (2007, «La responsabilidad civil médica...»: 30; 2007 «Una visión general...»: 90, nota 80). W. F. Hensel (2005), «The Disabling Impact of Wrongful Birth and Wrongful Life Actions», Harvard Civil Rights-Civil Liberties Law Review, 40, págs. 141-195, indica que los tribunales abrumadoramente rechazan las acciones por wrongful life [en Estados Unidos] (pág. 143), salvo en California, Nueva Jersey y Washington (págs. 161-162), y que en cambio aceptan las acciones por wrongful birth, que no obstante están excluidas por el legislador en Idaho, Indiana, Michigan, Missouri, Pensilvania y Utah (pág. 162, nota 123). 
Una de las peculiaridades de este tipo de responsabilidad, tanto contractual como extracontractual, consiste en que varios de sus principales elementos son problemáticos. No existe una unanimidad doctrinal ni sobre su concurrencia, ni sobre su extensión. Me refiero al daño (si se prefiere, lesión resarcible) y a la relación de causalidad entre la actuación u omisión sanitaria y tal daño, tanto en sentido físico natural como en sentido jurídico (o, si se prefiere evitar esta acepción, al título de imputación objetiva).

\section{EL DAÑo}

Las posibilidades pueden resumirse en seis daños: 1) el nacimiento del hijo, en sí mismo; 2) la lesión del derecho a abortar; 3) la privación de la toma de decisión sobre la interrupción del embarazo; 4) el impacto psíquico de encontrarse con un hijo discapacitado; 5) la manutención y gastos ordinarios asociados al hijo; y 6) los gastos extraordinarios derivados de la enfermedad.

\section{A) El mero nacimiento del hijo}

Pese a algunos pronunciamientos jurisprudenciales desafortunados, a los que luego se hará referencia, en general se admite que el nacimiento de un hijo no puede ser considerado un daño a efectos de la responsabilidad, con independencia de que esté sano o enfermo. Sería contrario al derecho a la vida, primero de los derechos fundamentales listados en la Constitución (art. 15, que abre la sección primera del capítulo segundo del título primero, rotulada precisamente «de los derechos fundamentales y de las libertades públicas») y en otros instrumentos internacionales ${ }^{38}$. Pugnaría con la dignidad de la persona, fundamento del orden político y de la paz social según el art. 10.1 de la Constitución, que la mera existencia de un ser humano fuera reputada como un daño para otro. Esto se afirma de modo claro por la jurisprudencia ${ }^{39}$.

38 El art. 3.2.b) de la Carta de los Derechos Fundamentales de la Unión Europea incluye «la prohibición de las prácticas eugenésicas, en particular las que tienen como finalidad la selección de las personas».

39 En palabras de la Sentencia del Tribunal Supremo de 19 de mayo de 2015 (sala 3a, recurso 4397/2010, ponente Jesús Cudero Blas): «Esta Sala ha declarado en ocasiones anteriores (sentencia de la Sección Sexta de 4 de noviembre de 2008, dictada en el recurso de casación núm. 4936/2004) que el nacimiento de un hijo no puede considerarse un dańo, "pues no cabe en el ordenamiento espańol lo que, en terminología inglesa, se denomina wrongful birth", ya que "no hay nacimientos equivocados o lesivos, pues el art. 15 de la Constitución implica que toda vida humana es digna de ser vivida”". La misma doctrina se había mantenido antes en la Sentencia del Tribunal 
La doctrina en general respalda esta consideración ${ }^{40}$. Aunque esto sea así en términos estrictamente jurídicos, desde el punto de vista psicológico no es infrecuente que la mujer embarazada conciba como un daño el nacimiento de su hijo discapacitado ${ }^{41}$.

\section{B) La lesión del derecho a abortar}

El segundo daño posible consiste en la lesión del derecho a abortar. Como es lógico, esto depende de la previa existencia de tal derecho. En Estados Unidos, como es conocido, el derecho a interrumpir el embarazo constituye un derecho fundamental derivado del «right to privacy» (derecho a la vida privada), un verdadero derecho constitucional ${ }^{42}$, a partir de la Sentencia del Tribunal Supremo Roe v. Wade ${ }^{43}$. Es algo comúnmente aceptado ${ }^{44}$. En cambio, la tendencia predominante en Europa es no considerar el aborto

Supremo (Sala 1a) de 23 de noviembre de 2007, recurso 4469/2000, ponente Encarnación Roca Trías.

40 R. de Ángel Yágüez (1999), «La segunda sentencia dictada por la Sala Primera del Tribunal Supremo en un caso de wrongful birth (4 de febrero de 1999). ¿Está en contradicción con lo resuelto en la sentencia de 6 de junio de 1997 sobre el mismo problema?», Revista de Derecho y Genoma Humano, 10, págs. 117-154 (págs. 141 y 152); J. L. Requero Ibáñez (2002), «El consentimiento informado y la responsabilidad patrimonial de las Administraciones», en Guerrero (dir.) (2002: 321-406, pág. 403); M. Navarro Michel (2006), "Comentario a la sentencia del Tribunal Supremo de 21 de diciembre de 2005", Cuadernos Civitas de Jurisprudencia Civil, 72, marginal 1930, págs. 1637-1657 (pág. 1650); De Verda y Beamonte y Chaparro Matamoros (2012: 27 y 43); A. Pérez-Tenessa (2001), «Sobre el diagnóstico prenatal como causa de responsabilidad», Revista de Administración Pública, 154, págs. 47-61 (pág. 55).

41 Como hace notar Hansel (2005: 187), a diferencia de otros grupos, con frecuencia los padres de un nasciturus discapacitado no tienen experiencia de la discapacidad. La posibilidad de contemplar solo los aspectos negativos, incrementados por los prejuicios sociales, no es desdeñable.

42 Aunque la Constitución no menciona expresamente el «right to privacy», se entiende por el Tribunal Supremo comprendido implícitamente en varias enmiendas (como la IX o la XIV).

43410 U.S. 113 (1973).

44 A simple título de ejemplo, D. A. Farber, W. N. Eskridge y P. P. Frickey (1993), Constitutional Law. Themes for the Constitution's Third Century, St. Paul, Minnesota: West Publishing Co. (págs. 503-540); G. Gunther (1992), Individual Rights in Constitutional Law, Westbury, New York: The Foundation Press, Inc., (págs. 177-207); J. A. Barron y C. T. Dienes (1991), Constitutional Law, St. Paul, Minnesota: West Publishing Co. (págs. 162-177). 
como un derecho constitucional, ni tan siquiera como un verdadero derecho, sino como un supuesto de actuación lícita y prevista por la ley ${ }^{45}$.

En Espańa, claramente bajo la vigencia de la primera regulación del aborto, contenida en el art. 417bis del Código Penal, la interrupción del embarazo no se concebía como derecho, sino como conducta despenalizada ${ }^{46}$. Así se infiere de la Sentencia del Tribunal Constitucional 53/1985, de 11 de abril.

La cuestión se plantea con más viveza a partir de la Ley Orgánica 2/2010, de 3 de marzo, de salud sexual y reproductiva y de la interrupción voluntaria del embarazo. Esta norma evita configurar el aborto como un derecho de modo expreso, algo que sí hace con la "maternidad libremente decidida" (art. 2.2) y con la adopción libre de «decisiones que afectan a su vida sexual y reproductiva sin más límites que los derivados del respeto a los derechos de las demás personas y al orden público garantizado por la Constitución y las Leyes» (art. 2.1). En cambio, respecto del aborto únicamente "garantiza el acceso a la interrupción voluntaria del embarazo en las condiciones que se determinan en esta Ley» (art. 12). Esta expresión obedece a una sugerencia del Consejo de Estado, en el dictamen emitido sobre el anteproyecto de ley ${ }^{47}$,

45 M. A. Glendon (1987), Abortion and Divorce in Western Law, Cambridge, Massachusetts: Harvard University Press.

46 Pérez-Tenessa (2001: 56). Se sostiene en la STS (Sala 1a) de 4 de febrero de 1999, recurso 2236/1994, ponente Jesús Marina Martínez-Pardo, FJ 4º. Sin embargo, Salàs Darrocha defendía que sí existía ya un verdadero derecho con esa legislación, aunque reconocía que «la cuestión no es pacífica» (2005: pág. 3 en la descarga digital del artículo, que no coincide con el paginado de la revista en papel).

47 Dictamen de 17 de septiembre de 2009, número 1384/2009, en el apartado IV de las consideraciones: «De la doctrina sentada por el Tribunal Constitucional en la que se mueve la presente consulta y del conjunto del propio texto del anteproyecto no resulta un derecho al aborto - algo desconocido en los ordenamientos de nuestro entorno susceptibles de ser tomados como modelos-, sobre el que el Tribunal Europeo de Derechos Humanos ha rehusado pronunciarse (TEDH/2007/20, caso Tysiac contra Polonia, par. 104), que ni siquiera se menciona en los instrumentos internacionales relativos a los derechos de la mujer (véase Res 48/104 de 20 de diciembre de 1993, art. 3) y cuya formulación carece de fundamento en nuestro ordenamiento jurídico. En efecto, una vez que, como antes se expuso, el Tribunal Constitucional ha sentado y reiterado la tesis de que el feto constituye un "tertium" independiente de la madre y que, aún sin ser titular de un derecho a la vida, sí es un bien jurídico digno de protección - en cuanto esperanza de vida-, resulta lógica una doble conclusión, a saber: de un lado, en caso de conflicto, puede considerarse su sacrificio en aras de un interés superior; incluso si, por hipótesis más adelante analizada, fuera la madre gestante la única que debiera hacer tal ponderación y tomar la decisión oportuna. Pero, de otro 
que negaba que se estuviese creando un derecho al aborto y entendía preferible una fórmula como la finalmente adoptada frente al reconocimiento de un derecho.

La repercusión de la Ley Orgánica 2/2010, de 3 de marzo, ya citada, en materia de wrongful birth es innegable: entre otros aspectos, permite el aborto hasta el final del embarazo "cuando se detecte en el feto una enfermedad extremadamente grave e incurable en el momento del diagnóstico y así lo confirme un comité clínico» (art. 15.c ${ }^{48}$ ), algo que no estaba autorizado bajo la vigencia del art. 417bis del antiguo Código Penal, pues limitaba a las 22 semanas el aborto por presumirse que el feto habría de nacer "con graves taras físicas o psíquicas». Como señala Macía, esto hace posible extender los supuestos de wrongful birth, en algunos casos, durante todo el embarazo ${ }^{49}$.

Sin embargo, en línea con el Consejo de Estado, cabe afirmar que no existe, como tal, un derecho al aborto consagrado en nuestro ordenamiento jurídico ${ }^{50}$. Se trata de una actuación libre y lícita, como tantas otras, que no tiene asociado un derecho sino una "garantía de acceso". En estas condiciones, no puede configurar un daño resarcible la lesión de un derecho subjetivo ${ }^{51}$.

lado, no puede reconocerse un derecho subjetivo — semejante al de propiedad - o un derecho personalísimo — como el que existe sobre el propio cuerpo- a eliminar tal bien, dotado de sustantividad propia, de relieve vital y, en consecuencia, de interés objetivo y general, como, tomando pie en la normativa francesa al respecto, ha reconocido expresamente el Tribunal Europeo de Derechos Humanos en Sentencia de 13 de febrero del 2003 (TEDH/2003/, caso Odièvre contra Francia, par. 45). Ello aconseja matizar la confusa y, por ende, polémica expresión del art. 12 del anteproyecto consultado, referente, según se precisa más adelante, no a un derecho al aborto sino a la prestación sanitaria requerida por la interrupción voluntaria del embarazo. Basta a estos efectos decir "se garantiza" puesto que la expresión "se reconoce" es propia de las declaraciones constitucionales de derechos fundamentales».

48 Además de las «anomalías fetales incompatibles con la vida» que, como señala A. Macía Morillo (2011: 89), no darían lugar al nacimiento de un nińo vivo, ni por tanto a una acción por wrongful birth.

49 Macía Morillo (2011: 94). Señala que esta es «la diferencia más relevante que introduce la nueva regulación sobre la interrupción voluntaria del embarazo en relación con las acciones de wrongful birth y wrongful life».

50 En igual sentido, De Verda y Beamonte y Chaparro Matamoros (2012: 43, en nota 30).

51 Esto supone discrepar con la afirmación de Ángel Yágüez de que «si tal derecho se niega, se tambalea cualquier argumentación basada en la alegación de que el médico, con su error, hizo imposible el recurso a la interrupción del embarazo», R. de Ángel Yágüez (2005), «Ante la cuarta sentencia de la Sala Primera en materia de wrongful birth: ¿̨es 
Ello no implica que no pueda existir otro tipo de dańo: en Espańa no solo existe responsabilidad, civil extracontractual o patrimonial de la Administración por el quebrantamiento de derechos subjetivos, en sentido estricto. La afección negativa a innumerables intereses, ámbitos personales o espacios de libertad también es indemnizable. A simple título de ejemplo, yo no tengo derecho a que mi hijo viva (el derecho a la vida es suyo), pero su muerte me ocasiona un daño moral por supuesto indemnizable.

\section{C) La privación de la toma de decisión sobre la interrupción del embarazo}

Se reconozca o no un derecho subjetivo a abortar, como tal, nadie duda de la facultad que tiene la mujer de interrumpir el embarazo de acuerdo con la citada Ley Orgánica 2/2010, de 3 de marzo. Implícita en ella está la toma de decisión. Uno de los motivos, sin relevancia jurídica durante las primeras catorce semanas de gestación, con ella a partir de ese momento, son las "graves anomalías en el feto» (art. 15, letra b, de la citada Ley Orgánica) ${ }^{52}$. Si estas se desconocen, por una mala práctica médica, la toma de decisión sobre la interrupción del embarazo se produce sin datos que pueden ser fundamentales desde el punto de vista subjetivo e incluso desde el punto de vista legal. La afectación negativa a este proceso de toma de decisión constituye un daño según la doctrina mayoritaria y la jurisprudencia. Es aceptado por Macía ${ }^{53}$ y otros muchos ${ }^{54}$, aunque no es unánime ${ }^{55}$.

posible hablar ya de una jurisprudencia?», Revista de Derecho y Genoma Humano, 22, págs. 179-206 (pág. 205).

52 Durante las primeras catorce semanas la sola petición de la embarazada, tras darle cierta información y transcurridos tres días, permite la práctica del aborto (art. 14 de la Ley Orgánica 2/2010, de 3 de marzo, ya citada).

53 Macía Morillo (2005: 396; 2007 «La responsabilidad civil médica...»: 24; 2007, «Una visión general...»: 83).

54 Ángel Yágüez (1999: 153); R. Bercovitz Rodríguez-Cano (1999), «Comentario a la sentencia del Tribunal Supremo de 4 de febrero de 1999», Cuadernos Civitas de Jurisprudencia Civil, 50, marginal 1373, págs. 841-859 (pág. 858); Martín Casals y Solé Feliú (2002: 1110; 2007: 533); Navarro Michel (2006: 1650-1651); De Verda y Beamonte y Chaparro Matamoros (2012: 33 y 43).

55 Garriga niega que el daño sea «la privación de la posibilidad de interrumpir el embarazo", por ser «una decisión que depende sólo de la voluntad de la mujer», aunque acepta como dańos el moral por el impacto emocional y el patrimonial por las necesidades económicas de hijo con la patología (M. Garriga Gorina (2003), «Negligencia en el diagnóstico prenatal», Indret, 3/2003, págs. 1-14, pág. 8). 


\section{D) El impacto psíquico de encontrarse con un hijo discapacitado}

El impacto psíquico de estar esperando un hijo discapacitado en un mundo ideal no debería existir, pues la discapacidad se asumiría como una forma distinta de la estadísticamente predominante, sin traumas ni miedos. Sin embargo, como la aceptación social de la discapacidad por desgracia aún no es la deseable, el impacto existe en muchas personas al comunicarles el diagnóstico, y no pueden evitarlo ${ }^{56}$. Sin embargo, si se ignora hasta el parto la discapacidad, se evita este eventual impacto psíquico, pero se podría producir otro, por el nacimiento del hijo. A diferencia de los daños anteriores, estos impactos se pueden dar en el padre o en la madre ${ }^{57}$. El impacto últimamente mencionado no existe si el hijo no llega a nacer por una interrupción voluntaria del embarazo. De ahí que la falta de información sobre la patología, contraria a la lex artis, en la medida en que impide tomar una decisión de interrumpir el embarazo, se relaciona con este daño. Varios autores lo aceptan ${ }^{58}$, así como alguna sentencia ${ }^{59}$.

\section{E) La manutención y gastos ordinarios asociados al hijo}

Con carácter general, se niega tanto por la jurisprudencia ${ }^{60}$ como por la doctrina ${ }^{61}$. Si el nacimiento en sí mismo no supone un daño, como se ha visto,

56 Quedan fuera de este trabajo los eventuales daños derivados de la concepción de un hijo enfermo por un fallo en la selección de los embriones en la fecundación «in vitro».

57 Pero no los hermanos, como indican Martín Casals y Solé Feliu (2007: 535-536), que critican la Sentencia del Tribunal Supremo (Sala 1a) de 18 de mayo de 2006, recurso 3337/1999, ponente José Antonio Seijas Quintana, que los reconoció para una hermana, confirmando al efecto el pronunciamiento de una Audiencia Provincial. En cambio, Salàs Darrocha (2005: pág. 6 de la descarga digital del artículo) reconoce legitimación activa también a hermanos y abuelos que convivan con el nacido.

58 Galán Cortés (2016: 581); Navarro Michel (2006: 1653); Martín Casals y Solé Feliu (2002: 1115-1116), que consideran que también han de satisfacerse al padre (2002: 1118); Ángel Yágüez (2002: 190). En cambio, Elizari indica que implica «una visión muy negativa de la discapacidad» (2010: 153).

59 STS (Sala 1a) de 6 de junio de 1997, recurso 165/1993, ponente Ignacio Sierra Gil de la Cuesta.

60 STS (Sala 3a) de 4 de noviembre de 2008, recurso 4936/2004, ponente Luis María Díez-Picazo Giménez.

61 Martín Casals y Solé Feliu (2002: 1117; 2007: 533); Navarro Michel (2006: 1654). 
tampoco sus consecuencias ordinarias. En este sentido, el derecho de alimentos entre parientes no constituye un daño indemnizable ${ }^{62}$.

\section{F) Los gastos extraordinarios derivados de la enfermedad}

Se diferencia del anterior en que se cińe exclusivamente a los mayores gastos derivados de la discapacidad, durante la vida del hijo. Tiene amplio respaldo doctrinal ${ }^{63}$, con algunas críticas ${ }^{64}$, y se reconoce en diversas sentencias de la Sala de lo Civil del Tribunal Supremo ${ }^{65}$, aunque alguna otra lo niega ${ }^{66}$. En la Sala de lo Contencioso-Administrativo del mismo Tribunal Supremo por lo general se excluía, pues se limitaba la indemnización al daño moral ${ }^{67}$,

62 Navarro Michel señala que «el deber legal de alimentos [...] no puede ser objeto de tráfico jurídico» (2006: 1654) y que «con independencia de cuál hubiese sido su decisión sobre el aborto, la mujer embarazada iba a tener un hijo y asumía su coste: lo que no asumía es el mayor coste derivado de su discapacidad" (2006: 1657).

63 Así, R. de Ángel Yágüez (1996: 153-154; 2002: 190), Galán Cortés (2016: 581); Martín Casals y Solé Feliú (2002: 1117); I. Vivas Tesón (2003), «La responsabilidad civil médica en los supuestos de wrongful birth y wrongful life: análisis jurisprudencial», Revista de Derecho Patrimonial, 11, págs. $403-415$ (pág. 408); M. Martín Casals y J. Solé Feliú (2004), «Responsabilidad civil por la privación de la posibilidad de abortar (wrongful birth)», Indret, 2/2004, págs. 1-12 (pág. 10); Salàs Darrocha (2005: pág. 11 de la descarga digital del artículo); Navarro Michel (2006: 1654).

64 Elizari (2010: 156-157) señala que son gastos futuros, hipotéticos e inciertos, que en ocasiones corresponden a prestaciones de la Seguridad Social, de la Consejería autonómica de salud, de los servicios sociales autonómicos o municipales. Propone que sea un criterio para elevar la cuantía indemnizatoria por daño moral. Además, pone de relieve que no hay garantía de que la indemnización que se concede a los padres redunde en beneficio del hijo.

65 Aunque sin mucho detalle ni precisión, se reconocen en la primera Sentencia, de 6 de junio de 1997, recurso 165/1993, ponente Ignacio Sierra Gil de la Cuesta, así como en otras posteriores, por ejemplo, Sentencias de 18 de diciembre de 2003, recurso 766/1998, ponente Jesús Corbal Fernández, de 21 de diciembre de 2005, recurso 1986/1999, ponente José Antonio Seijas Quintana, de 19 de julio de 2007, recurso 2853/2000, ponente Román García Varela, y de 15 de septiembre de 2015, recurso 2675/2013, ponente José Antonio Seijas Quintana. Con toda claridad en la Sentencia de 31 de mayo de 2011, recurso 128/2008, ponente José Antonio Seijas Quintana.

66 STS de 6 de julio de 2007, recurso 3036/2000, ponente José Antonio Seijas Quintana.

67 Así lo indica Elizari (2010: 154-155). SSTS de 4 de noviembre de 2005, recurso 5377/2001, ponente Agustín Puente Prieto, 21 de febrero de 2006, recurso 1117/2002, ponente Octavio Juan Herrero Pina, 30 de junio de 2006, recurso 217/2005, ponente Enrique Lecumberri Martí, 10 de mayo de 2007, recurso 4779/2003, ponente 
si bien las sentencias más recientes tienden a reconocerlo ${ }^{68}$. La adición de esta partida indemnizatoria determina que la cuantía total de las indemnizaciones en ocasiones sea significativa, de varios cientos de miles de euros ${ }^{69}$.

Margarita Robles Fernández, y 16 de octubre de 2007, recurso 9768/2003, ponente Margarita Robles Fernández.

68 En la Sentencia de 14 de marzo de 2007, recurso 8017/2002, ponente Margarita Robles Fernández, se confirma una sentencia de la Audiencia Nacional que había indemnizado también por las necesidades que comportaban los tratamientos médico y rehabilitador. Luego muy claramente se admite «la lesión puramente económica consistente en el notablemente mayor coste de criar una hija con síndrome de Down» en la Sentencia de 4 de noviembre de 2008, recurso 4936/2004, ponente Luis María Díez-Picazo Giménez, al igual que en las Sentencias de 25 de mayo de 2010, recurso 3021/2008, ponente Santiago Martínez-Vares García; 16 de junio de 2010, recurso 4403/2008, ponente Segundo Menéndez Pérez; 27 de octubre de 2010, recurso 4978/2007, ponente Segundo Menéndez Pérez; y 28 de marzo de 2012, recurso 2362/2011, ponente Enrique Lecumberri Martí.

691200000 euros en la sentencia que fue confirmada por la del Tribunal Supremo (Sala $\left.1^{a}\right)$ de 15 de septiembre de 2015, recurso 2675/2013, ponente José Antonio Seijas Quintana; 300 506,05 euros en la sentencia que luego fue confirmada por la del Tribunal Supremo (Sala 1a) de 14 de marzo de 2013, recurso 1785/2010, ponente José Antonio Seijas Quintana; 280000 euros en la Sentencia del Tribunal Supremo (Sala $3^{\text {a) }}$ de 28 de marzo de 2012, recurso 2362/2011, ponente Enrique Lecumberri Martí; 739463,97 euros en la Sentencia que fue confirmada por la del Tribunal Supremo (Sala 1a) de 4 de noviembre de 2010, recurso 444/2007, ponente José Antonio Seijas Quintana; 601317,10 euros en la Sentencia que fue confirmada por la del Tribunal Supremo (Sala 3a) de 27 de octubre de 2010, recurso 4978/2007, ponente Segundo Menéndez Pérez; 150000 euros más una pensión vitalicia de 1500 euros revalorizable con arreglo al IPC en la Sentencia del Tribunal Supremo (Sala 3a) de 16 de junio de 2010, recurso 4403/2008, ponente Segundo Menéndez Pérez; 500000 euros en la Sentencia que fue confirmada por la del Tribunal Supremo (Sala 3a) de 25 de mayo de 2010, recurso 3021/2008, ponente Santiago Martínez-Vares García; 751 265,13 euros en las sentencias luego confirmadas por la del Tribunal Supremo (Sala 1a) de 17 de noviembre de 2008, recurso 1560/2003, ponente José Antonio Seijas Quintana; 420708,47 euros en la sentencia que fue confirmada por la del Tribunal Supremo (Sala 3a) de 4 de noviembre de 2008, recurso 4936/2004, ponente Luis María DíezPicazo Giménez; 666229 euros en la Sentencia que fue confirmada por la del Tribunal Supremo (Sala 1a) de 24 de octubre de 2008, recurso 1894/2003, ponente José Antonio Seijas Quintana. 


\section{LA RELACIÓN DE CAUSALIDAD}

Una vez expuesta una síntesis del daño en la responsabilidad por wrongful birth, conviene hacer referencia a la relación de causalidad, pues de otro modo luego sería difícil de valorar la aplicación a este tipo de indemnizaciones de la Convención sobre los Derechos de las Personas con Discapacidad de 2006. De nuevo, no se trata de agotar el tema, sino de repasar con rapidez una serie de cuestiones suscitadas por los autores.

Ríos de tinta han corrido desde el derecho romano sobre la relación de causalidad en materia de responsabilidad aquiliana ${ }^{70}$. Ciertamente, constituye un elemento imprescindible de la responsabilidad por daños y como tal se exige literalmente, por ejemplo, en el art. 1902 del Código Civil. Ha sido estudiada con amplitud también por los penalistas, especialmente en el siglo XIX.

No es objeto de estas líneas abordar la relación de causalidad con carácter general, ni tampoco la imputación objetiva. Baste decir, siguiendo a DíezPicazo $^{71}$, que en el ámbito del derecho penal, Von Buri en 1855 intentó una concepción "científica» de la causalidad, equiparándola a la condición sine qua non. El ejercicio consistía en determinar si la consecuencia se habría dado de suprimir el factor: en caso afirmativo, no es considerado causa, en caso negativo, sí lo es. Esta teoría, llamada de la equivalencia de condiciones, próxima a la causalidad físico-natural, dio lugar a conocidos excesos, justamente criticados por la doctrina. Para evitarlos se adoptaron otras teorías, como los juicios de probabilidad o la causalidad adecuada, que tendían a evitar juicios causales anómalos. En definitiva, se trataba de discernir si determinados hechos causantes eran o no relevantes, a efectos de atribuir un resultado a una persona. Esto pasaba por adoptar un criterio más físico-natural de la causalidad (causalidad de hecho, cause in $\mathrm{fact}^{2}$ ) y remitir a otro juicio los criterios jurídicos para asociar un resultado a un agente ${ }^{73}$. Tal juicio integra la imputación objetiva, que llega

70 Recuérdese, por ejemplo, el famoso texto del Digesto $(9,2,52)$, tomado de Alfeno, sobre los dos carros tirados por mulas en la cuesta del Capitolio que caen hacia atrás, arrastrando el primero al segundo y atropellando este a un muchacho, ante lo que se preguntaba contra cuál debía dirigir la acción.

71 (2000: 334-349).

72 Así las denominan P. Salvador Coderch y A. Fernández Crende (2006), «Causalidad y responsabilidad», Indret, Revista para el Análisis del Derecho, 329, págs. 1-25 (pág. 3).

73 En palabras de Colina, «debemos diferenciar entre los problemas causales, que son puramente de hecho, y la cuestión jurídica relativa a la determinación de en qué supuestos el resultado dańoso puede ser atribuido, imputado o puesto a cargo del sujeto que ha realizado la conducta ligada causalmente a dicho daño. Nos encontramos, pues, ante la distinción entre la causalidad física, material o fáctica y la denominada 
a considerar una equivocación hablar de "causalidad jurídica» ${ }^{74}$. La imputación era objetiva y no subjetiva, pues presuponía una imputación subjetiva determinada con la causalidad como condición sine qua non (si bien hay autores para los que la imputación subjetiva es identificada con la negligencia o el dolo ${ }^{75}$ ). En España la distinción entre causalidad e imputación objetiva fue reconocida por la Sala Segunda del Tribunal Supremo desde principios de los años ochenta y tuvo temprana acogida también entre los tratadistas de la responsabilidad patrimonial de la Administración, entre los que me permito destacar a Beladíez ${ }^{76}$.

Además de las cuestiones generales sobre el nexo de causalidad ${ }^{77}$, en materia de wrongful birth existe una especificidad importante: dado que si la madre no pensaba abortar en ningún caso hubiese sido irrelevante (o al menos mucho menos relevante ${ }^{78}$ ) la falta de información previa sobre la discapacidad o patología del hijo, se interpone entre la acción u omisión y el daño una decisión hipotética de carácter voluntario, en sentido estricto imposible de conocer a posteriori. Esta dificultad es ampliamente reconocida ${ }^{79}$.

"causalidad jurídica" o "concepto normativo de la causalidad", el cual se asocia a la conocida 'teoría de la imputación objetiva'», R. Colina Garea, "La relación de causalidad», en Pena López (dir.) (2004: 77-105, pág. 88).

74 F. Pantaleón (1990), "Causalidad e imputación objetiva», en el libro colectivo Centenario del Código Civil, tomo II, págs. 1561-1591 (pág. 1563). Afirma que la distinción entre causalidad e imputación objetiva no había «aparecido nunca en la jurisprudencia de nuestro Tribunal Supremo» (pág. 1566). Véase también su comentario al art. 1902 del Código Civil (1991), en Comentario del Código Civil, Madrid: Ministerio de Justicia, tomo II, págs. 1971-2003, en el que asevera que el concepto jurídico de la causalidad jurídica es «metodológicamente incorrecto» (pág. 1981).

75 Como F. Peña López (2004), «El criterio de imputación (II.-La culpabilidad)», en Pena López (2004: 107-124) y Salvador Coderch y Fernández Crende (2006: 19).

76 M. Beladíez Rojo (1997), Responsabilidad e imputación de daños por el funcionamiento de los servicios públicos, Madrid: Tecnos (especialmente págs. 96-103).

77 Por ejemplo, si la madre se negó a realizar una prueba diagnóstica que habría detectado la enfermedad, obviamente no puede imputar a los servicios médicos la falta de información sobre la patología: es el caso del Dictamen del Consejo de Estado de 28 de septiembre de 2006, 1613/2006.

78 En efecto, cabría plantearse que el impacto emocional de dar a luz a un hijo con una discapacidad habría sido menguado, incluso en madres contrarias al aborto, de haber podido conocerlo con antelación y prepararse psíquicamente para ello. Sin embargo, ninguna sentencia del Tribunal Supremo acoge este razonamiento para indemnizar a madres que hayan excluido expresamente el aborto (tal vez porque no han demandado).

79 Galán Cortés (2016: 570): «[E]l análisis que la relación de causalidad requiere nos llevará a una pregunta clave: ¿puede decirse que hay relación de causalidad entre la 
Esto se resuelve por parte de autores como Macía y Navarro distinguiendo entre dańos. A juicio de Macía Morillo, el problema de la relación de causalidad es insoluble si se configura como daño el no haber abortado. En cambio, si el daño consiste en no haber tenido la opción de hacerlo, se salva tal problema ${ }^{80}$. En este caso, resulta irrelevante lo que habría hecho la madre: basta con que se le haya privado de la posibilidad de decidir ${ }^{81}$.

Esta tesis ha tenido acogida en la Sentencia de la Sala $1^{\text {a }}$ del Tribunal Supremo de 31 de mayo de $2011^{82}$, que casó una sentencia desestimatoria de la responsabilidad de la Audiencia Provincial de Castellón de la Plana,

culpa del médico (o, en su caso, la acción —u omisión— de la Administración o entidades sanitarias) y el "desenlace" acontecido, cuando no es posible asegurar con toda certeza que la madre habría acudido al aborto si hubiere conocido la enfermedad que aquejaba al feto?». En términos parecidos, Ángel Yágüez explica que en estos casos de wrongful birth ocurre que «un elemento de los constitutivos del esquema dogmático de la responsabilidad civil, cual es la relación de causalidad, se complica extraordinariamente. En efecto, en los casos que nos ocupan se plantea la obligada pregunta de si la mujer ya embarazada habría optado por abortar si hubiese conocido la enfermedad que afectaba al feto» (1999: 121). Navarro Michel expresa esto mismo con claridad: «La tentación de inventar el deseo o disponibilidad de abortar es enorme para los padres. Si el éxito de la reclamación de indemnización se basa únicamente en la declaración de la mujer, tiempo después del evento, de que habría abortado, sería ir en contra de sus propios intereses (económicos) decir que no hubiese abortado» (2006: 1656). También A. M. Romero Coloma (2010), «Las acciones de wrongful birth y wrongful life en el ordenamiento jurídico español (especial referencia a la responsabilidad civil médica)», Revista Crítica de Derecho Inmobiliario, 722, págs. 2559-2608 (pág. 2598); Pacheco-Jiménez (2011: 11); Vicandi Martínez (2013: 54-56).

80 Macía Morillo (2005: 476; 2007 «La responsabilidad civil médica...»: 24; 2007, «Una visión general...»: 83-84; 2009: 198-202).

81 Macía Morillo (2008: 205-206). Lo expresa Navarro Michel en estos términos: «Las dificultades del nexo causal se reducen considerablemente si el eje de la cuestión se centra en la vulneración a la autonomía personal, en la privación de la posibilidad de adoptar una decisión sobre la interrupción del embarazo. Si decimos que la conducta médica impide a la mujer tomar una decisión sobre el aborto eugenésico no será necesario alegar el propósito o la disponibilidad de abortar. No sabemos qué hubiese decidido, pero sí sabemos que podía haber decidido y la negligencia del demandado ha impedido el ejercicio de su autonomía personal. Pudiendo legalmente tomar una decisión sobre la interrupción del embarazo se le priva de la posibilidad de hacerlo» (2006: 1657).

82 Recurso 128/2008, ponente José Antonio Seijas Quintana. En el mismo sentido, con cita de esta sentencia, se pronuncia la de la misma Sala y ponente de 14 de marzo de 2013, recurso 1785/2010. 
confirmatoria a su vez de la del Juzgado de Instrucción. Se discutía si una ecografía debía haber detectado "anomalías fetales», cosa que se excluía en las sentencias de instancia por cuanto la diagnosis de las «malformaciones» de este tipo era muy difícil y la paciente había sido informada de que los resultados de la ecografía no eran definitivos para la detección de "anomalías morfológicas» ${ }^{83}$ del feto: el Tribunal Supremo en cambio entendió que el diagnóstico había sido erróneo, contrario a la lex artis. Lo más relevante consiste en el tratamiento que la sentencia hace de la afirmación de instancia de que no se podía presumir la voluntad de abortar de la demandante, máxime cuando la ecografía se había practicado fuera del plazo legal para ello. La Sentencia del Tribunal Supremo asevera que «el daño es independiente de la decisión de abortar» y que resulta "del hecho de haber privado negligentemente a la madre de la posibilidad de decidir acerca de su situación personal y familiar».

En cualquier caso, la cuestión de la privación de una toma de decisión tiene algo de artificiosidad. Está claro que a todas las madres que se les priva de modo contrario a la lex artis ad hoc de información sobre una discapacidad del feto se les quita de la posibilidad de abortar por este motivo. Aunque por supuesto no todas las mujeres lo harían. Sin embargo, la privación de la opción de hacer algo solo tiene sentido si ese algo tiene cierta plausibilidad. Una opción resulta valiosa si la facultad o derecho que comprende también lo es para el sujeto. Por poner un ejemplo algo tosco, si alguien me concede gratuitamente una opción de compra de un inmueble a un precio elevado y además muy superior al de mercado, a mí, que además no tengo recursos para afrontar la compra, la opción no me resulta valiosa. $\mathrm{Ni}$, por tanto, su pérdida puede ser configurada como un daño para mí.

La privación de la posibilidad de decidir si abortar o no sencillamente es irrelevante para mujeres que jamás lo harían, o no lo harían en el embarazo en cuestión, y en cambio resulta muy relevante en caso contrario. La dificultad en cuanto al nexo causal no queda por tanto resuelta.

El modo habitual de afrontar esta cuestión consiste en presumir la voluntad de abortar de la mujer en caso de haber conocido la patología o discapacidad del feto, pues a fin de cuentas solicita una indemnización por este motivo en los procesos, como demandante. Ángel Yágüez ${ }^{84}$ entiende que basta con la

83 Reproduzco la terminología de la sentencia, ciertamente mejorable.

84 Ángel Yágüez (1996, parte II: 149-150; 2002: 191; 2005: 201-202; 2006, «La quinta sentencia del Tribunal Supremo en un caso de wrongful birth se puede decir que ya existe una jurisprudencia en la materia», Práctica Derecho de Daños, 38, págs. 5-23, en nota 3, pág. 7). Según este autor, la afirmación de la madre no puede ponerse «en tela 
afirmación de la mujer en el proceso, algo que Bercovitz ${ }^{85}$ considera incluso innecesario: es la otra parte la que debe probar, si está en condiciones de hacerlo, que la conducta de la madre habría sido la alternativa, es decir, proseguir con el embarazo ${ }^{86}$. Esta opinión tiene respaldo en múltiples sentencias de la Sala $3^{\text {a }}$ del Tribunal Supremo ${ }^{87}$.

Ante la dificultad de saber cuál habría sido la decisión de la madre si hubiese conocido en el momento la patología de su hijo, se abren diversas posibilidades teóricas:

1) Denegar toda indemnización, pues un elemento clave del curso causal no se ha acreditado.

2) Aplicar un "estándar probabilístico suave» ${ }^{88}$, dada la dificultad de una prueba plena, y aceptar indicios de voluntad de abortar (como la solicitud de pruebas diagnósticas adicionales, el sometimiento a la amniocentesis, que conlleva riesgos para el feto, o la práctica de previos abortos).

3) Aplicar un «estándar probabilístico suave», dada la dificultad de una prueba plena, y aceptar indicios de voluntad de no abortar (como las convicciones religiosas o el nacimiento de otros hijos con patologías similares).

de juicio». Lo mismo considera Salàs Darrocha (2005: pág. 11 de la descarga digital del artículo). M. J. Alonso Parreño (2005), «Demandas judiciales por nacimiento con discapacidad (wrongful birth, wrongful life): perspectiva jurídica», en www.down21. org, 14 págs. (pág. 12 de la descarga del documento), también considera necesaria la declaración de la madre, que no puede ser discutida ni negada.

85 R. Bercovitz Rodríguez-Cano (2002), «Comentario a la sentencia del Tribunal Supremo de 7 de junio de 2002», Cuadernos Civitas de Jurisprudencia Civil, 59, marginal 1614, págs. 857-865.

86 Martín Casals y Solé Feliu (2002: 1113) configuran la afirmación de que la madre no hubiese abortado como una excepción, cuya carga de la prueba corresponde a quien la emplea (art. 217.3 de la Ley de Enjuiciamiento Civil). La cuestión es si de verdad se trata de una excepción o de un elemento fundamental de la pretensión, en cuyo caso no operaría tal regla sobre la carga probatoria.

87 SSTS de 30 de junio de 2006, recurso 217/2005, ponente Enrique Lecumberri Martí, 14 de marzo de 2007, recurso 8017/2002, ponente Margarita Robles Fernández, 16 de octubre de 2007, recurso 9768/2003, ponente Margarita Robles Fernández (véase la crítica de De Verda y Beamonte y Chaparro Matamoros, 2012: 39, en nota 26), y 28 de marzo de 2012, recurso 2362/2011, ponente Enrique Lecumberri Martí.

88 Uso la terminología de L. Medina Alcoz (2016), «Los hechos en el Derecho administrativo. Una aproximación», Revista Española de Derecho Administrativo, 177, págs. 103-158 (págs. 124-126). 
4) Admitir como acreditado el elemento de la relación causal con la afirmación de la madre.

5) Admitir como acreditado el elemento de la relación causal con la sola pretensión indemnizatoria de la madre.

La práctica judicial respalda la quinta posibilidad, de hecho con frecuencia indistinguible de la cuarta. Con una sola excepción ${ }^{89}$, las muy pocas sentencias que han utilizado el argumento de la falta de prueba de la voluntad de abortar siempre lo han hecho como argumento de refuerzo de otro principal (normalmente, ausencia de quebrantamiento de la lex artis ad hoc) ${ }^{90}$. Con posterioridad, además, aquel argumento ha sido repudiado de forma expresa por diversas sentencias ${ }^{11}$. Y además, cuando se han manejado "indicios» de cuál podría haber sido la decisión, siempre han sido favorables al aborto, como argumento dialéctico frente a la negación de prueba. Por consiguiente, se ha establecido jurisprudencialmente, en realidad, una especie de presunción iuris et de iure de que si la madre pide una indemnización por wrongful birth, habría abortado de haber conocido la patología del feto.

Adicionalmente se plantea otra cuestión sobre la relación de causalidad, en el sentido jurídico antes expresado. Asumiendo que la conducta del personal sanitario que no proporcionó información suficiente o correcta ha privado a la mujer de la toma de decisión sobre el aborto, cabe establecer un vínculo entre tal conducta y este daño. Sin embargo, los gastos extraordinarios derivados de la enfermedad, ¿pueden ser imputados objetivamente al personal sanitario, que en absoluto causó la enfermedad? Macía se opone ${ }^{92}$, pues no cabe establecer tal imputación objetiva cuando los daños caen fuera del ámbito o finalidad de protección de la norma sobre la que se funda la responsabilidad del demandado. En otros términos, solo son imputables al agente (sanitario, en este caso) productor del daño los perjuicios que recaigan sobre aquellos bienes o intereses que la norma busca proteger (en este caso la regulación del aborto, que tutela exclusivamente a la mujer en su decisión de abortar o no $)^{93}$.

89 La Sentencia de la Sala $1^{\text {a }}$ del Tribunal Supremo de 7 de junio de 2002, recurso 3834/1996, ponente Pedro González Poveda.

90 Por ejemplo, Sentencia de 4 de febrero de 1999 (Sala 1a), recurso 2236/1994, ponente Jesús Marina Martínez-Pardo.

91 Como la de 30 de junio de 2006 (Sala 3a), recurso 217/2005, ponente Enrique Lecumberri Martí.

92 Macía (2005: 459; 2007, «Una visión general...»: 84-85).

93 Macía (2009: 199-202; 2007 «La responsabilidad civil médica...»: 24; 2007, «Una visión general...»: 89-90). 
Elizari manifiesta que el nexo causal en este caso no parece claro ${ }^{94}$. El asunto es relevante, pues, como se ha visto, las indemnizaciones por este daño alcanzan cuantías muy elevadas, en comparación con las que se otorgan por el simple dańo moral. Sin embargo, como se ha indicado, aunque rechazados durante los primeros años por la jurisdicción contencioso-administrativa, la Sala Tercera del Tribunal Supremo giró en el año 2007 y comenzó a concederlos.

\section{LA LEX ARTIS AD HOC EN LA JURISPRUDENCIA CIVIL Y CONTENCIOSO-ADMINISTRATIVA}

Resumidas en las páginas anteriores algunas cuestiones de configuración del daño y de la relación de causalidad en sentido jurídico (añadiendo la imputación objetiva) de la responsabilidad por wrongful birth, antes de pasar a estudiar el impacto que sobre todo ello puede tener la Convención sobre los Derechos de las Personas con Discapacidad de 2006, parece conveniente hacer una somera referencia a la cuestión de la lex artis, tal y como es abordada por jurisprudencia en la materia.

La jurisprudencia española no es muy voluminosa, ni tampoco muy antigua. En el orden jurisdiccional civil comenzó con la Sentencia de la Sala $1^{\text {a }}$ del Tribunal Supremo de 6 de junio de $1997^{95}$; en la Sala $3^{\text {a }}$ del mismo tribunal con la de 4 de noviembre de $2005^{96}$. Como sucede tantas veces, y más en supuestos en los que participan dos órdenes jurisdiccionales, incurre en algunas contradicciones y adolece de falta de claridad ${ }^{97}$. De hecho, la segunda sentencia de la Sala $1^{\text {a }}$ del Tribunal Supremo, de 7 de junio de $2002^{98}$, contenía una

94 Elizari (2010: 155 y 156, en nota 57).

95 Recurso de casación 165/1993, ponente Ignacio Sierra Gil de la Cuesta. Véase el comentario de M. Ureña Martínez (1997), «Comentario a la sentencia del Tribunal Supremo de 6 de junio de 1997», Cuadernos Civitas de Jurisprudencia Civil, 45, marginal 1223, págs. 1105-1116. Una crítica a la sentencia se formuló por J. E. Bustos Pueche (1997), «Un caso de voluntarismo judicial: la sentencia del Tribunal Supremo de 6 de junio de 1997», La Ley, Revista Española de Doctrina, Jurisprudencia y Bibliografía, tomo 5 de Jurisprudencia, marginal D-250, págs. 1699-1701. También la critican De Verda y Beamonte y Chamorro Matamoros (2012: 31-32).

96 Recurso 5377/2001, ponente Agustín Puente Prieto.

97 De Verda y Beamonte y Chaparro Matamoros (2012: 42) indican que «falta una doctrina jurisprudencial uniforme».

98 Recurso de casación 3834/1996, ponente Pedro González Poveda. Véanse los comentarios de Martín Casals y Solé Feliu (2002), Ángel Yágüez (2002), Bercovitz Rodríguez-Cano (2002), X. Cecchini Rosell (2003), «El deber de información del médico. 
doctrina contraria a la primera, algo tempranamente advertido ${ }^{99}$, y a su vez fue contradicha por la tercera, la de 18 de diciembre de $2003^{100}$, que no siguió la línea de la anterior, sin explicación alguna de la variación de criterio ${ }^{101}$. Y tanto la primera como la tercera se trataban de casos de responsabilidad patrimonial de la Administración, con condenas a servicios autonómicos de salud.

Con posterioridad, la Sala de lo Civil del Tribunal Supremo continuó dictando algunas sentencias en litigios de responsabilidad contra la Administración, como la de 21 de diciembre de $2005^{102}$. A esta han seguido otras sentencias de la misma Sala del Tribunal Supremo, como las 18 de mayo de $2006^{103}, 19$ de julio de $2007^{104}, 23$ de noviembre de $2007^{105}$, las tres en casos de síndrome de Down, o la de 24 de octubre de $2008^{106}$, todas ellas respaldando indemnizaciones por wrongful birth, cuyo análisis excedería con mucho los límites de este trabajo. Lo mismo cabe decir respecto de las sentencias de la

Nacimiento de niño con síndrome de Down. Concepto de daño y relación de causalidad», Revista de Derecho Patrimonial, 10, págs. 181-192 y Garriga Gorina (2003).

99 Martín Casals y Solé Feliu (2002: 1109-1111); Ángel Yágüez (2002: 183-202); Bercovitz Rodríguez-Cano (2002: 864).

100 Recurso 766/1998, ponente Jesús Corbal Fernández. Véanse los comentarios de Martín Casals y Solé Feliu (2004), A. Macía Morillo (2004), «Comentario a la sentencia del Tribunal Supremo de 18 de diciembre de 2003", Cuadernos Civitas de Jurisprudencia Civil, 66, marginal 1765, págs. 1023-1040, muy crítica, y R. de Ángel Yágüez (2005). Vuelve Macía sobre esta sentencia años después, también para cuestionarla (2007, «La responsabilidad civil médica...»: 34; 2007 «Una visión general...»: 93).

101 Lo que es criticado por Martín Casals y Solé Feliú (2004: 8) y por Macía Morillo (2004:1030).

102 Recurso 1986/1999, ponente José Antonio Seijas Quintana. Véanse los comentarios de Navarro Michel (2006) y Ángel Yágüez (2006). Condenó al Servicio Vasco de Salud (Osakidetza) y a una compañía aseguradora a que indemnizasen. De nuevo el orden jurisdiccional competente no parece que era el civil.

103 Recurso 3337/1999, ponente José Antonio Seijas Quintana. Véase el comentario de Martín Casals y Solé Feliú (2007).

104 Recurso 2853/2000, ponente Román García Varela.

105 Recurso 4469/2000, ponente Encarnación Roca Trías. Véase el comentario de M. M. Méndez Serrano (2008), "Comentario a la sentencia del Tribunal Supremo de 23 de noviembre de 2007», Cuadernos Civitas de Jurisprudencia Civil, 77, marginal 2052, págs. 853-865.

106 Recurso 1894/2003, ponente José Antonio Seijas Quintana. Se reprocha al médico una omisión, no haber solicitado una ecografía de nivel II antes de la $22^{\text {a }}$ semana. Véase el comentario de Macía Morillo (2008), que critica que el Tribunal no tenga en cuenta que las ecografías de este tipo no siempre permiten detectar las patologías (2008: 200-202 y 206). 
Sala $3^{\text {a }}$ del mismo tribunal, a partir de la segunda dictada en la materia, la de 30 de junio de $2006^{107}$, en igual sentido.

Ambos órdenes jurisdiccionales, civil y contencioso-administrativo, tienen, en este período, algunos elementos importantes en común en materia de responsabilidad médica o sanitaria. Uno de ellos, tal vez el principal, es la exigencia de un quebrantamiento de la lex artis ad hoc ${ }^{108}$. En general se entiende que si la conducta médica no la vulneró, aunque desde un punto de vista natural causara el daño, no hubo relación de causalidad en sentido jurídico ${ }^{109} \mathrm{o}$, según otra aproximación, no hubo un título de imputación objetiva del daño al profesional de la salud. En el ámbito civil, salvo que otra cosa se pacte, el contrato de arrendamiento de servicios (con la excepción de la medicina voluntaria o satisfactiva) solo comprende una obligación de medios dentro de la lex artis, no de resultados ${ }^{110}$, y si además no se quebranta esta no puede hablarse de culpa ${ }^{111}$. En materia de responsabilidad patrimonial de la Administración, en ocasiones se defiende que solo se responde en la práctica por funcionamiento anormal de la Administración ${ }^{112}$, y que el parámetro de normalidad consiste en la observancia de la lex artis ad hoc ${ }^{113}$, o bien que

107 Recurso 217/2005, ponente Enrique Lecumberri Martí.

108 Con todas las dificultades que esto conlleva, destacadas por M. Alonso Pérez (2000), «La relación médico-enfermo, presupuesto de responsabilidad civil (en torno a la 'lex artis')», en Moreno Martínez (coord.) (2000: 13-53). Un análisis detallado en J. Guerrero Zaplana (2006), Las reclamaciones por la defectuosa asistencia sanitaria, 5a ed., Valladolid: Lex Nova (págs. 148-159). Recientemente, F. J. Bauzá Martorell (2016), «Presunción de culpa. La deducción de negligencia en la responsabilidad patrimonial de la Administración», Revista de Administración Pública, 201, págs. 373-411 (págs. 404-405).

109 J. E. Peces Morate (2002), «La responsabilidad patrimonial de la Administración sanitaria», en J. García Bernaldo de Quirós (dir.), Nuevas líneas doctrinales y jurisprudenciales sobre la responsabilidad patrimonial de la Administración, Cuadernos de Derecho Judicial II-2002, págs. 183-211 (págs. 190-194). En igual sentido, Guerrero Zaplana (2002: 73-76).

110 M. M. Naveira Zarra (2004), «Responsabilidad civil de los profesionales», en Pena López (dir.) (2004: 281-296, en págs. 293-295). También Galán Cortés (2016: 139147); este autor critica la excepción para la medicina voluntaria o satisfactiva, que también piensa que constituye una obligación de medios (2016: 148-174).

111 Ángel Yágüez (2005: 200-201), Moncada Miranda, Aedo Barrena y Coleman Vega (2015: 36, nota 40). Esta parece ser la aproximación de la Sentencia del Tribunal Supremo (Sala 1a) de 24 de octubre de 2008, recurso 1894/2008, ponente José Antonio Seijas Quintana, en su FJ 20.

112 Cueto Pérez (2009: 860-864).

113 F. J. Villar Rojas (1996), La responsabilidad de las Administraciones sanitarias: fundamento y limites, Barcelona: Praxis (págs. 130-135). 
el daño no constituye una lesión resarcible por falta de antijuridicidad ${ }^{114}$, porque no son indemnizables los hechos o circunstancias que no se puedan prever o evitar según el estado de los conocimientos de la ciencia o de la técnica existentes en el momento de producción del daño ${ }^{115}$ (art. 34.1 de la Ley 40/2015, de 1 de octubre, de Régimen Jurídico del Sector Público).

De esta relevancia de la lex artis ad hoc se extraen consecuencias en materia de responsabilidad por wrongful birth ${ }^{116}$. Así, el Tribunal Supremo no concede indemnización si no se acredita la infracción a la lex artis, como tampoco lo hace el Consejo de Estado ${ }^{117}$. Un ejemplo de ello fue la Sentencia del Tribunal Supremo de 4 de febrero de $1999^{118}$, la segunda que se dictó por la Sala de lo Civil en la materia, confirmatoria de una previa de la Audiencia Provincial de Salamanca ${ }^{119}$. El supuesto también era de dudosa competencia de la jurisdicción civil, pues se demandaba también al Ministerio de Sanidad y Consumo y al Instituto Nacional de la Salud ${ }^{120}$. Otros ejemplos fueron las sentencias de la misma Sala de lo Civil del Tribunal Supremo de 19 de junio

114 R. Vázquez del Rey Villanueva (2003), «La responsabilidad patrimonial de la Administración sanitaria», en La responsabilidad patrimonial del Estado, vol. II, Boletín del Ilustre Colegio de Abogados de Madrid, 3a época, 24, págs. 11-63 (págs. 16-21). En este sentido, por ejemplo, Sentencia del Tribunal Supremo (Sala 3a) de 22 de noviembre de 2011, 4353/2009, ponente Segundo Menéndez Pérez.

115 Cueto Pérez (2009: 865-869).

116 Ángel Yágüez (1996, parte II: 143); Navarro Michel (2006: 1646); Macía Morillo (2008: 208); Pacheco-Jiménez (2011: 5).

117 Dictámenes de 18 de diciembre de 2008, 1828/2008; 11 de octubre de 2006, 1667/2006; 22 de diciembre de 2005, 1814/2005; 9 de junio de 2005, 832/2005; 11 de mayo de 2005, 684/2005; 20 de enero de 2005, 2894/2004; 22 de julio de 2004, 1717/2004; 21 de diciembre de 2000, 3385/2000; 23 de marzo de 2000, 867/2000; 19 de noviembre de 1998, 2870/1998.

118 Recurso 2236/1994, ponente Jesús Marina Martínez-Pardo. La interpretación que hago de esta sentencia es calificada de «tranquilizadora» y hasta de «un tanto hipócrita» por Ángel Yágüez (2005: 204-205) por centrarse en la lex artis y relegar el otro argumento proporcionado por la sentencia, que el aborto era una simple hipótesis. No es eso lo que interpretó este autor en un trabajo anterior (2002: 200-202). Sin embargo, pienso que el argumento central de la sentencia, el más extenso y el primero que se aborda en el FJ $5^{\circ}$, es que no hubo infracción a la lex artis, como habían declarado las dos sentencias de instancia.

119 Véase el comentario de Ángel Yágüez (1999: 146), que se muestra conforme con el fallo.

${ }^{120}$ De hecho, este punto fue criticado en el voto particular del magistrado Román García Varela y por Bercovitz Rodríguez-Cano (1999: 855). 
de $2007^{121}$ y de 17 de noviembre de $2008^{122}$, que confirmaron sendas sentencias desestimatorias de las Audiencias Provinciales, o las sentencias de la Sala de lo Contencioso-Administrativo de 23 de enero de 2012 223 , 28 de marzo de $2012^{124}$ y 18 de junio de $2012^{125}$, también confirmatorias de las sentencias de instancia.

En cambio, cuando se aprecia infracción a la lex artis en la falta de información, se declara la responsabilidad, como en la Sentencia de la Sala $1^{\text {a }}$ del Tribunal Supremo de 6 de julio de $2007^{126}$, que casó una sentencia absolutoria en la que no se apreciaba tal infracción, en un supuesto de síndrome de Down (y ello pese a que entre los condenados figura el Instituto Catalán de Salud, con lo que la competencia del orden jurisdiccional civil resulta más que discutible); o en las sentencias de la misma sala de 4 de noviembre de $2010^{127}$ y 14 de marzo de $2013^{128}$. Igual criterio sigue la Sala $3^{\text {a }}$ del Tribunal Supremo, por ejemplo en su Sentencia de 16 de junio de 2010, en otro caso de síndrome de Down $^{129}$.

\section{LA CONVENCIÓN SOBRE LA PROTECCIÓN DE LAS PERSONAS CON DISCAPACIDAD}

Expuesto el estado de la cuestión de la responsabilidad por wrongful birth, tanto en sus elementos configuradores como en la jurisprudencia, pasamos ahora a proyectar sobre ella la Convención sobre la Protección de las Personas con Discapacidad, hecha en Nueva York el 13 de diciembre de 2006 y ratificada por Espańa mediante instrumento de 23 de noviembre de 2007.

${ }^{121}$ Recurso 2047/2000, ponente Juan Antonio Xiol Ríos. Se trataba de un niño con síndrome de Down. Véase el comentario favorable de De Verda y Beamonte y Chaparro Matamoros (2012: 37-41).

122 Recurso 1560/2003, ponente José Antonio Seijas Quintana.

123 Recurso 43/2010, ponente Celsa Pico Lorenzo.

124 Recurso 6454/2010, ponente Enrique Lecumberri Martí.

125 Recurso 4113/2010, ponente Enrique Lecumberri Martí.

126 Recurso 3036/2007, ponente José Antonio Seijas Quintana. Véase el comentario de J. C. Galán Cortés (2008), "Comentario a la sentencia del Tribunal Supremo de 6 de julio de 2007», Cuadernos Civitas de Jurisprudencia Civil, 76, marginal 2027, págs. 279-290.

127 Recurso 444/2007, ponente José Antonio Seijas Quintana.

128 Recurso 1785/2010, ponente José Antonio Seijas Quintana.

129 Recurso 4403/2008, ponente Segundo Menéndez Pérez. 
A lo largo de la historia se ha tratado la discapacidad de diversos modos, que Cuenca Gómez ${ }^{130}$ sintetiza en tres: el modelo de la "prescindencia», el modelo médico y el modelo social ${ }^{131}$. Con arreglo al primero, las causas de la discapacidad son religiosas (un castigo divino) y las personas que se ven afectadas por ella son innecesarias para la sociedad: constituyen una carga y sus vidas no merecen la pena ser vividas ${ }^{132}$. En consecuencia, se prescinde de ellas, bien mediante la eugenesia, bien mediante la marginación: a lo sumo, se les trata como un objeto de caridad.

El modelo médico o rehabilitador, que se consolida tras la Primera Guerra Mundial, al relacionarse la discapacidad con los heridos de guerra ${ }^{133}$, concibe la discapacidad como un fenómeno netamente individual. Tiene un sesgo «biológico»: como su origen es biológico, las «soluciones» también han de serlo ${ }^{134}$. Su tratamiento se orienta a prevenir, erradicar, curar, minimizar o paliar la deficiencia, para lograr la integración en la sociedad, compensando en otro caso a quienes no lo logran. Se adoptan por tanto medidas en los ámbitos de salud, Seguridad Social, asistencia, protección social y derecho civil (incapacitación) ${ }^{135}$. Aunque este modelo supuso un avance importante, ha sido objeto de distintas críticas: visión parcial de la persona con discapacidad como un enfermo o paciente, sin considerarlo íntegramente como un ciudadano de pleno derecho; intento de «normalizar», hacia una «normalidad» a

130 P. Cuenca Gómez (2012), Los derechos fundamentales de las personas con discapacidad. Un análisis a la luz de la Convención de la $O N U$, Cuadernos de la Cátedra de Democracia y Derechos Humanos de la Universidad de Alcalá, 7, págs. 26-42. Una versión más reducida puede consultarse en R. de Asís Roig, M. C. Barranco Avilés, P. Cuenca Gómez y A. Palacios Rizzo (2010), «Algunas reflexiones generales sobre el impacto de la Convención Internacional de los Derechos de las Personas con Discapacidad en el Derecho español», en P. Cuenca Gómez (ed.), Estudios sobre el impacto de la Convención Internacional sobre los Derechos de las Personas con Discapacidad en el ordenamiento jurídico español, Madrid: Dykinson, págs. 11-33 (págs. 13-16).

131 Hensel (2005: 149-150) no considera el modelo de la "prescindencia» y en cambio a los modelos médico y social añade un tercero, el de la minoría. Según este, los discapacitados constituyen un grupo minoritario que debe luchar en el campo de los derechos humanos como otros grupos para lograr evitar la discriminación y estigmatización, sin esperar pasivamente a que la sociedad actúe en su favor.

132 R. Kayess y P. French (2008), «Out of Darkness into Light? Introducing the Convention on the Rights of Persons with Disabilities», Human Rights Law Review, 8, págs. 1-34 (pág. 5).

133 Cuenca Gómez (2012: 27, nota 14).

${ }^{134}$ Hensel (2005: 146-147).

135 Cuenca Gómez (2012: 28-29). 
la que ha de tender la persona con discapacidad, so pena de no poder gozar de todos los derechos; y encasillamiento de las personas con discapacidad en función de sus limitaciones, con los consiguientes estereotipos que generan sobreprotección ${ }^{136}$, irrelevancia de la experiencia subjetiva de la persona ${ }^{137}$. En definitiva, este modelo "considera a la persona con discapacidad como un ser inferior que tiene un menor valor o, mejor, que sólo tendrá el mismo valor que las personas sin discapacidad en la medida en que pueda adaptarse a la sociedad» ${ }^{138}$. Como señala Hensel, "pese a sus avances significativos, tanto legal como socialmente, el modelo médico continúa conformando las bases de gran parte del pensamiento estadounidense e internacional sobre la discapacidad $»^{139}$.

Por fin, el denominado modelo social de la discapacidad surge por la propia acción de las personas con discapacidad y de ciertas organizaciones, y trata de trasladar el "problema» del individuo a la sociedad. La discapacidad constituye una situación social en la que se encuentran determinados individuos: ya no es un déficit individual, sino un déficit social, por tanto una cuestión de exclusión y de discriminación, en definitiva, de derechos humanos ${ }^{140}$. Un ejemplo conocido es el de la persona que se desplaza en silla de ruedas y no puede acceder a un edificio con escaleras: la discapacidad con respecto al edificio no es tal, lo que ocurre es que la construcción solo se diseñó para quienes podían caminar ${ }^{141}$, excluyéndole. El Estado y la sociedad tienen la responsabilidad de acabar con la exclusión y garantizar el pleno respeto de la dignidad y la igualdad de las personas con discapacidad, que pasan de ser «objetos» de tratamientos médicos y rehabilitadores a «sujetos» de derechos ${ }^{142}$. La Convención Internacional de Naciones Unidas sobre los Derechos de las Personas con Discapacidad, adoptada por la Asamblea General de las Naciones Unidas el 13 de diciembre de 2006, claramente se enmarca en este modelo, aunque tiene elementos del modelo anterior ${ }^{143}$.

136 Cuenca Gómez (2012: 29-32).

137 Hensel (2005: 146).

138 Cuenca Gómez (2012: 32).

139 «Despite significant advances, both legally and socially, the medical model continues to form the basis of much of American and International thinking on disability", Hensel (2005: 174) [traducción del autor].

140 Cuenca Gómez (2012: 34). Kayess y French (2008: 6) explican que el «modelo social» surgió en el Reino Unido a mediados de la década de los sesenta. Hensel lo data en los finales de esta misma década en los Estados Unidos (2005: 147).

141 Hensel (2005: 148).

142 Cuenca Gómez (2012: 34 y 41-42). Kayes y French (2008: 14).

143 Asís Roig, Barranco Avilés, Cuenca Gómez y Palacios Rizzo (2010: 17). 
Como señala MacKay ${ }^{144}$, la Declaración Universal de Derechos Humanos de 1948 prevé la no discriminación por diversos motivos o por «cualquier otra condición» (art. 2), lo que claramente incluye la discapacidad. En teoría, según este autor, podría pensarse que era innecesaria una nueva convención en materia de derechos humanos. Sin embargo, la Declaración Universal fue seguida a los pocos ańos por otros instrumentos generales (como el Pacto Internacional de Derechos Civiles y Políticos o el Pacto Internacional de Derechos Económicos, Sociales y Culturales de 1966), y por otros específicos sobre no discriminación, como la Convención Internacional sobre la Eliminación de todas las formas de Discriminación Racial de 1965 y la Convención para la Eliminación de todas las formas de Discriminación contra la Mujer de 1979. En estas circunstancias, como dijo la Alta Comisionada para los Derechos Humanos de las Naciones Unidas, pese a que los instrumentos internacionales generales en teoría protegían a las personas con discapacidad, en la práctica no proporcionaban la adecuada protección ${ }^{145}$.

La Convención sobre los Derechos de las Personas con Discapacidad produjo un notable entusiasmo desde su inicio: fue el tratado sobre derechos humanos más rápidamente negociado de la historia ${ }^{146}$ y en la sesión de apertura a la firma, el 30 de marzo de 2007, fue firmada por ochenta y un Estados y por la Unión Europea, el número más alto de firmas en la sesión de apertura de cualquier otro tratado en materia de derechos huma$\operatorname{nos}^{147}$. España lo firmó ese día y lo ratificó mediante instrumento de 23 de noviembre de $2007^{148}$. Sin embargo, tal vez no se han extraído todas las consecuencias jurídicas que esta ratificación lleva consigo. Como señalan Kayess y French, la Convención «ha modificado, transformado y añadido

${ }^{144}$ D. Mackay (2007), "The United Nations Convention on the Rights of Persons with Disabilities», Syracuse Journal of International Law and Commerce, 34, págs. 323-331 (págs. 323-324).

145 "There is no doubt that the existing human rights system was meant to promote and protect the rights of persons with disabilities. There is also no doubt that the existing standards and mechanisms have in fact failed to provide adequate protection in the specific case of persons with disabilities. It is clearly time for the United Nations to remedy this shortcoming» (palabras de Louise Arbour, citadas por Mackay, 2007: 326). Por lo demás, ninguno de los convenios citados mencionaba a los discapacitados como una categoría protegida (Kayess y French, 2008: 12).

146 Así lo dijo el secretario general de las Naciones Unidas (Mackay, 2007: 327; Kayess y French, 2008: 2; Cuenca Gómez, 2012: 44).

147 Kayess y French (2008: 2).

148 Boletín Oficial del Estado de 21 de abril de 2008. 
nuevos elementos a los conceptos tradicionales de los derechos humanos en cuestiones clave» $^{149}$.

La finalidad de la Convención queda clara desde su comienzo, pues su art. 1 , rubricado "propósito", dispone:

El propósito de la presente Convención es promover, proteger y asegurar el goce pleno y en condiciones de igualdad de todos los derechos humanos y libertades fundamentales por todas las personas con discapacidad, y promover el respeto de su dignidad inherente.

Las personas con discapacidad incluyen a aquellas que tengan deficiencias físicas, mentales, intelectuales o sensoriales a largo plazo que, al interactuar con diversas barreras, puedan impedir su participación plena y efectiva en la sociedad, en igualdad de condiciones con las demás.

Como se aprecia, ya desde el primer artículo de la Convención queda clara la directriz de la igualdad entre las personas con discapacidad y el resto de los individuos, tanto en "todos los derechos humanos y libertades fundamentales» como en la «participación plena y efectiva en la sociedad». Su texto va mucho más allá de la igualdad, pues incorpora elementos como el respeto por la diferencia y la aceptación de las personas con discapacidad como parte de la diversidad y la condición humanas ${ }^{150}$, su protagonismo respecto de sus propias vidas y en la sociedad ${ }^{151}$, la igualdad de oportunidades ${ }^{152}$ y los «ajustes razonables» ${ }^{153}$ que se deben hacer para hacer posible su participación en la sociedad.

Sin embargo, el umbral mínimo es la igualdad respecto de las personas sin discapacidad. Esto se manifiesta en la absoluta prohibición de discriminación, que se invoca ya desde el preámbulo. En efecto, en su párrafo h los Estados parte reconocen:

[Q]ue la discriminación contra cualquier persona por razón de su discapacidad constituye una vulneración de la dignidad y el valor inherentes del ser humano.

149 Kayes y French (2008: 32) [traducción del autor].

150 Art. 3, letra d.

151 Que se manifiesta, entre otros puntos, en los arts. 3, letras a y c, 13 (acceso a la justicia), 19 (derecho a vivir de forma independiente y a ser incluido en la comunidad), 20 (movilidad personal), 21 (libertad de expresión y de opinión y acceso a la información), 26 (habilitación y rehabilitación), 27 (trabajo y empleo), 29 (participación en la vida política y pública), y 30 (participación en la vida cultural, las actividades recreativas, el esparcimiento y el deporte).

152 Art. 3, letra e.

153 Arts. 2, 5.3, 13.1, 14.2, 24.2.c), 24.5 y 27.1.i). 
El concepto de discriminación se da en el art. 2, párrafo cuarto, en estos términos:

Por «discriminación por motivos de discapacidad» se entenderá cualquier distinción, exclusión o restricción por motivos de discapacidad que tenga el propósito o el efecto de obstaculizar o dejar sin efecto el reconocimiento, goce o ejercicio, en igualdad de condiciones, de todos los derechos humanos y libertades fundamentales en los ámbitos político, económico, social, cultural, civil o de otro tipo. Incluye todas las formas de discriminación, entre ellas, la denegación de ajustes razonables.

De acuerdo con ello, el segundo principio general de la Convención, en su art. 3, tras el del respeto a su dignidad, es el de no discriminación. Y, en consecuencia, los Estados miembros en el art. 4 se obligan, entre otras cosas, a:

b) Tomar todas las medidas pertinentes, incluidas medidas legislativas, para modificar o derogar leyes, reglamentos, costumbres y prácticas existentes que constituyan discriminación contra las personas con discapacidad;

d) Abstenerse de actos o prácticas que sean incompatibles con la presente Convención y velar por que las autoridades e instituciones públicas actúen conforme a lo dispuesto en ella;

Estas obligaciones continúan en el art. 5, dedicado a la «igualdad y no discriminación», cuyo tenor es este:

1. Los Estados Partes reconocen que todas las personas son iguales ante la ley y en virtud de ella y que tienen derecho a igual protección legal y a beneficiarse de la ley en igual medida sin discriminación alguna.

2. Los Estados Partes prohibirán toda discriminación por motivos de discapacidad y garantizarán a todas las personas con discapacidad protección legal igual y efectiva contra la discriminación por cualquier motivo.

3. A fin de promover la igualdad y eliminar la discriminación, los Estados Partes adoptarán todas las medidas pertinentes para asegurar la realización de ajustes razonables.

4. No se considerarán discriminatorias, en virtud de la presente Convención, las medidas específicas que sean necesarias para acelerar o lograr la igualdad de hecho de las personas con discapacidad.

Como es sabido, no toda desigualdad supone una discriminación. Así lo explica el Tribunal Constitucional en su Sentencia 41/2013, de 14 de febrero ${ }^{154}$ :

${ }^{154}$ Ponente Manuel Aragón Reyes (FJ 6º). 
Examinada la cuestión desde la perspectiva de la cláusula general de igualdad, se hace necesario recordar que, como tiene declarado este Tribunal desde la STC22/1981, de 2 de julio (recogiendo al respecto la doctrina del Tribunal Europeo de Derechos Humanos en relación con el art. 14 del Convenio europeo para la protección de los derechos humanos y de las libertades fundamentales), el principio de igualdad no implica en todos los casos un tratamiento legal igual con abstracción de cualquier elemento diferenciador de relevancia jurídica, de manera que no toda desigualdad de trato normativo respecto a la regulación de una determinada materia supone una infracción del mandato contenido en el art. $14 \mathrm{CE}$, sino tan sólo las que introduzcan una diferencia entre situaciones que puedan considerarse iguales, sin que se ofrezca y posea una justificación objetiva y razonable para ello, pues, como regla general, el principio de igualdad exige que a iguales supuestos de hecho se apliquen iguales consecuencias jurídicas y, en consecuencia, veda la utilización de elementos de diferenciación que quepa calificar de arbitrarios o carentes de una justificación razonable.

De esta suerte, para que sea constitucionalmente lícita la diferencia de trato es necesario que las consecuencias jurídicas que se deriven de tal distinción sean proporcionadas a la finalidad perseguida, de suerte que se eviten resultados excesivamente gravosos o desmedidos. En suma, el principio de igualdad en la ley no sólo exige que la diferencia de trato resulte objetivamente justificada, sino también que supere un juicio de proporcionalidad sobre la relación existente entre la medida adoptada, el resultado producido y la finalidad pretendida.

Por tanto, una diferencia de trato entre quienes están en igual circunstancia será discriminatoria cuando esté fundada en uno de los "criterios odiosos» enumerados en el art. 14 de la Constitución o cuando se base en «otra condición o circunstancia personal o social» sin justificación objetiva y razonable y sin superar además un juicio de proporcionalidad. Esto es aceptado por la doctrina ${ }^{155}$.

155 Por todos, L. M. Díez-Picazo Giménez (2013), Sistema de Derechos Fundamentales, 4a ed., Cizur Menor: Civitas (pág. 187): «Para que haya vulneración del principio de igualdad ante la ley o discriminación, no basta un trato distinto, sino que es imprescindible que éste sea arbitrario o injustificado. El aspecto clave de la igualdad en el contenido de la norma estriba, pues, en determinar qué criterios de diferenciación normativa son legítimos y cuáles, en cambio, resultan ilegítimos. A este respecto, es preciso recordar que, junto a la prohibición expresa de usar determinados criterios (raza, sexo, religión, etc.), el art. $14 \mathrm{CE}$ recoge también una cláusula genérica, relativa a «cualquier otra condición o circunstancia personal o social». Algo similar ocurre en el art. $14 \mathrm{CEDH}$ y en el art. 21 CDFUE. De aquí que haya dos clases de discriminación: la consistente en la utilización de algunos de los criterios de diferenciación expresamente prohibidos, y la reconducible a la mencionada cláusula genérica». 
Como señala Ribotta, «la prohibición de discriminación del derecho antidiscriminatorio se basa en identificar cuáles son los criterios injustos de discriminación basándose en la identificación de los grupos tradicionalmente discriminados» ${ }^{156}$.

Así las cosas, la ratificación del Convenio sobre los Derechos de las Personas con Discapacidad determina para el derecho español que nunca tenga una justificación objetiva y razonable una diferencia de trato que se funde en la discapacidad como tal. De algún modo esta convención ha venido a añadir al listado del art. 14 de la Constitución, si bien con un menor rango normativo, otro criterio "odioso" y prohibido: la discapacidad.

Esto se ratifica en el art. 63 de la Ley General de derechos de las personas con discapacidad y de su inclusión social, texto refundido, aprobado por Real Decreto Legislativo 1/2013, de 29 de noviembre:

Se entenderá que se vulnera el derecho a la igualdad de oportunidades de las personas con discapacidad, definidas en el art. 4.1, cuando, por motivo de o por razón de discapacidad, se produzcan discriminaciones directas o indirectas, discriminación por asociación, acosos, incumplimientos de las exigencias de accesibilidad y de realizar ajustes razonables, así como el incumplimiento de las medidas de acción positiva legalmente establecidas [cursivas nuestras].

Obviamente, el trato desigual prohibido por discriminatorio se refiere a la discapacidad como tal, no a algunas de sus manifestaciones. En consecuencia, serían antijurídicas por discriminatorias eventuales normas que, a título de ejemplo, consideraran la discapacidad sin más como justificación para la incapacitación, o para privar del derecho al voto o al matrimonio. Esto no implica que algunas formas de discapacidad puedan ser tenidas en cuenta por el legislador para extraer consecuencias, de ordinario de tipo tuitivo pero que pueden limitar derechos. Así, algunas patologías pueden justificar que se incapacite a un discapacitado, precisamente para protegerle a él y a su patrimonio, o que se le prive del sufragio activo, para que no sea manipulado por terceros. Pero no se tomarían estas decisiones por ser discapacitado, sin más, sino por padecer la patología en cuestión en el caso concreto. Esto, como es evidente, se aplica tanto a eventuales normas como a decisiones jurisdiccionales o administrativas. Todas ellas tienen la carga de motivar adecuadamente cualesquiera restricciones de derechos de discapacitados, detallando por qué en el supuesto

156 S. Ribotta (2010), «La Convención Internacional sobre los Derechos de las Personas con Discapacidad y el Derecho antidiscriminatorio español. Desafíos y ajustes que la Convención le exige al Derecho antidiscriminatorio español», en Cuenca Gómez (ed.) (2010: 449-477, pág. 458). 
se adoptan. En definitiva, se trata de "promover el respeto de su dignidad inherente», como expresa el art. 1 de la Convención, antes citado.

Como es sabido, la Ley Orgánica 2/2010, de 3 de marzo, de salud sexual y reproductiva y de la interrupción voluntaria del embarazo, permite la interrupción del embarazo durante las primeras catorce semanas, a petición de la mujer (art. 14). Sin embargo, en su art. 15 dispone:

Excepcionalmente, podrá interrumpirse el embarazo por causas médicas cuando concurra alguna de las circunstancias siguientes:

a) Que no se superen las veintidós semanas de gestación y siempre que exista grave riesgo para la vida o la salud de la embarazada y así conste en un dictamen emitido con anterioridad a la intervención por un médico o médica especialista distinto del que la practique o dirija. En caso de urgencia por riesgo vital para la gestante podrá prescindirse del dictamen.

b) Que no se superen las veintidós semanas de gestación y siempre que exista riesgo de graves anomalías en el feto y así conste en un dictamen emitido con anterioridad a la intervención por dos médicos especialistas distintos del que la practique o dirija.

c) Cuando se detecten anomalías fetales incompatibles con la vida y así conste en un dictamen emitido con anterioridad por un médico o médica especialista, distinto del que practique la intervención, o cuando se detecte en el feto una enfermedad extremadamente grave e incurable en el momento del diagnóstico y así lo confirme un comité clínico.

Desde el punto de vista de la discapacidad resultan problemáticas las letras b) y c). En efecto, bastan "riesgo de graves anomalías en el feto" para configurar un régimen excepcional de aborto, distinto del general. Y lo que sean tales "graves anomalías" no está en absoluto determinado: se decide sin ningún tipo de control por parte de los dos médicos especialistas que lo afir$\operatorname{man}^{157}$. El texto de la Ley Orgánica lleva implícito el planteamiento de que una vida con tales graves anomalías es menos valiosa que las de los restantes fetos, con lo que puede ser suprimida con más facilidad, en plazos más amplios. Y esto se impulsa hasta el extremo en la letra c), pues «una enfermedad extremadamente grave e incurable», situación en la que están muchos nacidos,

157 El único control sería el penal, en caso de denuncia o querella por aborto «fuera de los casos permitidos por la Ley» (art. 145.1 del Código Penal), con lo que el razonamiento es circular. La Ley Orgánica exige que los médicos que firman el «riesgo de graves anomalías» sean distintos del que practique o dirija el aborto, pero pueden pertenecer a la misma clínica. 
por lo demás, permite prescindir por completo de los plazos para la interrupción del embarazo. El diagnóstico, confirmado por un comité clínico, posibilita el aborto de fetos cercanos al nacimiento a término, que podrían vivir de modo independiente de la madre inmediatamente. Como es obvio, se está configurando un tratamiento legal excepcional y mucho menos favorable para los fetos con "graves anomalías» o con enfermedades «extremadamente graves e incurables». Su dignidad, precisamente por su discapacidad, no se respeta de modo adecuado, pues en vez de promover medidas para favorecer su integración en la sociedad se dan mayores facilidades para su eliminación, como algo indeseable. De modo implícito se considera de distinto valor la vida en función de la capacidad o discapacidad. Con las genéricas expresiones del legislador se está produciendo una discriminación contraria a la Convención. Así lo reconoce, por ejemplo, la profesora Palacios ${ }^{158}$.

Esto ha dado lugar a la intervención del Comité sobre los Derechos de las Personas con Discapacidad, órgano creado por la Convención sobre los Derechos de las Personas con Discapacidad y regulado en sus arts. 34 a 39. En efecto, en su sexto período de sesiones (septiembre de 2011), en sus observaciones finales, bajo el epígrafe «Principales motivos de preocupación y recomendaciones», indicaba:

17. El Comité toma nota de la Ley No 2/2010, de 3 de marzo de 2010, sobre la salud sexual y reproductiva, que despenaliza la interrupción voluntaria del embarazo, permite que se ponga fin al embarazo durante las primeras 14 semanas e incluye dos casos específicos en los que se amplían los plazos para el aborto si el feto tiene una discapacidad: hasta las 22 semanas de gestación cuando exista un «riesgo de graves anomalías en el feto», y después de 22 semanas de gestación cuando, entre otras cosas, «se detecte en el feto una enfermedad extremadamente grave e incurable». El Comité también toma nota de las explicaciones del mantenimiento de esta distinción dadas por el Estado parte.

18. El Comité recomienda al Estado parte que suprima la distinción hecha en la Ley No 2/2010 en cuanto al plazo dentro del cual la ley permite que se interrumpa un embarazo por motivos de discapacidad exclusivamente ${ }^{159}$.

158 A. Palacios (2010), «¿Por qué el aborto eugenésico basado en discapacidad es contrario a la Convención Internacional sobre los Derechos de las Personas con Discapacidad?», accesible en: http://www.convenciondiscapacidad.es/Noticias/Informe\%20Agustina\%20Palacios\%20def.pdf.

159 Naciones Unidas CRPD/C/ESP/CO/1. Accesible en: http://tbinternet.ohchr.org/_ layouts/treatybodyexternal/Download.aspx?symbolno=CRPD $\% 2 \mathrm{fC} \% 2 \mathrm{fESP} \% 2 \mathrm{fCO}$ $\% 2$ f1\&Lang=en. 
Esta recomendación se ha reiterado por parte del Comité a otros países que han introducido regímenes jurídicos similares al español, por ejemplo el caso de Austria ${ }^{160}$ o Hungría ${ }^{161}$. En cambio, no resulta de aplicación a aquellos Estados, como Italia, en que no existe un régimen especial de aborto embriopático, o por enfermedades o malformaciones del feto ${ }^{162}$.

Se podría suscitar la cuestión de la personalidad jurídica para negar la discriminación, en atención a que el feto carece de ella. Cabría entender que la discriminación prohibida es entre personas, con lo que no siéndolo el nasciturus no habría tal. En apoyo de esta tesis podría incluso mencionarse la antes citada Ley General de derechos de las personas con discapacidad y de su inclusión social ${ }^{163}$, que en su art. 7 proclama el derecho a la igualdad para las «personas con discapacidad» («Las personas con discapacidad tienen los mismos derechos que los demás ciudadanos conforme a nuestro ordenamiento jurídico»), y emplea la misma expresión en el art. 63, antes transcrito.

La mejor forma de visualizar el escaso sentido que tiene esta objeción es plantearse la hipótesis de una regulación del aborto que permita un plazo general y otro más extenso cuando el feto sea de sexo femenino (o de raza negra, por ejemplo $)^{164}$. ¿Alguien mantendría que una eventual legislación de este tipo

${ }^{160}$ Naciones Unidas, Committee on the Rights of Persons with Disabilities, Concluding observations on the initial report of Austria, adopted by the Committee at its tenth session, 2-13 September 2013: CRPD/C/AUT/CO/1, párrafo 15. Accesible en: http://tbinternet.ohchr.org/_layouts/treatybodyexternal/Download.aspx?symbol no=CRPD $\% 2 \mathrm{fC} \% 2 \mathrm{fAUT} \% 2 \mathrm{fCO} \% 2 \mathrm{f} 1 \& \mathrm{Lang}=\mathrm{en}$.

161 Naciones Unidas, Committee on the Rights of Persons with Disabilities, Concluding observations on the initial report of Hungary, adopted by the Committee at its eighth session, 1728 September 2012: CRPD/C/HUN/CO/1, párrafo 18. Accesible en: http://tbinternet.ohchr.org/_layouts/treatybodyexternal/Download.aspx?symbol no=CRPD $\% 2 \mathrm{fC} \% 2 \mathrm{fHUN} \% 2 \mathrm{fCO} \% 2 \mathrm{f} 1 \&$ Lang=en.

162 Macía (2007, «La responsabilidad civil médica...»: 17; 2007 «Una visión general...»: 77 , en nota 40, y 78). En realidad, el supuesto de riesgo para la mujer puede comprender las malformaciones o enfermedades del feto: pero no son estas por sí solas las que justifican el aborto, sino su incidencia sobre la salud de la madre. El art. 6.b) de la Ley de 22 de mayo de 1978, número 194, de Normas para la tutela social de la maternidad y sobre la interrupción voluntaria del embarazo, dispone como causa de aborto: "quando siano accertati processi patologici, tra cui quelli relativi a rilevanti anomalie o malformazioni del nascituro, che determinino un grave pericolo per la salute fisica o psichica della donna».

163 Texto refundido, aprobado por Real Decreto Legislativo 1/2013, de 29 de noviembre.

164 Palacios (2010: 3). Ciertamente, el caso de la discapacidad tiene sus peculiaridades con respecto a otros criterios «odiosos», pues en derecho de daños las lesiones con 
no sería discriminatoria por razón de sexo (o de raza)? Las prácticas en China y en la India de abortar de modo sistemático los fetos femeninos, aunque nada tienen que ver con las normas, suponen sin duda conductas discriminatorias por parte de las mujeres embarazadas, o de los familiares que les fuerzan o les impulsan a abortar.

Por lo demás, la Convención no supedita el reconocimiento de los derechos que en ella figuran a que el discapacitado tenga o no reconocida la personalidad jurídica. Cierto es que se refiere a los discapacitados con la expresión «las personas discapacitadas», pero la palabra "persona» no se emplea en sentido técnico jurídico. El mejor ejemplo es el art. 12.1, que prevé:

Los Estados Partes reafirman que las personas con discapacidad tienen derecho en todas partes al reconocimiento de su personalidad jurídica ${ }^{165}$.

Si los discapacitados fuesen ya "personas con discapacidad», sería absurdo plasmar su derecho al reconocimiento de su personalidad jurídica. En consecuencia, la Convención no restringe sus derechos a quienes, padeciendo discapacidad, se les haya reconocido legalmente la personalidad jurídica ${ }^{166}$.

El que los nascituri no gocen de personalidad jurídica no implica que no pueda existir una discriminación en el régimen jurídico de la interrupción de embarazo. El propio preámbulo de la Ley Orgánica 2/2010, de 3 de marzo, de salud sexual y reproductiva y de la interrupción voluntaria del embarazo, indica:

Pues si bien «los no nacidos no pueden considerarse en nuestro ordenamiento como titulares del derecho fundamental a la vida que garantiza el art. 15 de la

secuelas que discapacitan son indemnizables. No es indiferente, a estos efectos, la entidad de las lesiones. Sin embargo, la regulación de la interrupción voluntaria del embarazo no contempla la vertiente indemnizatoria, y además no es igual una condición innata (como puede ser el sexo o la discapacidad por una patología congénita) o una condición provocada forzosamente. Una operación de cambio de sexo hecha contra la voluntad del sujeto sería probablemente delictiva y, desde luego, indemnizable.

165 Sobre la incidencia que este artículo (no solo el apartado transcrito) pueda tener en derecho civil español, véase M. J. García Alguacil (2016), Protección jurídica de las personas con discapacidad, Madrid: Reus, págs. 23-28.

166 Por lo demás, el derecho a la vida se reconoce a todos los «seres humanos» en el art. 10, que tiene este tenor: «Los Estados Partes reafirman el derecho inherente a la vida de todos los seres humanos y adoptarán todas las medidas necesarias para garantizar el goce efectivo de ese derecho por las personas con discapacidad en igualdad de condiciones con las demás». 
Constitución» esto no significa que resulten privados de toda protección constitucional (STC 116/1999). La vida prenatal es un bien jurídico merecedor de protección que el legislador debe hacer eficaz.

En esa protección que ofrece el legislador a la vida prenatal no pueden existir discriminaciones, ni por los criterios constitucionalmente «odiosos» del art. 14, ni tampoco por razón de discapacidad.

Todos estos razonamientos tienen su aplicación en materia de wrongful birth. A efectos de su análisis, conviene aludir primero a la dimensión social del fenómeno, para luego acometer la estrictamente individual.

Respecto de la sociedad en su conjunto, con carácter general este tipo de acciones conlleva un impacto colectivo en las personas con discapacidad. En palabras de Hensel:

Los litigios de wrongful birth y wrongful life pueden imponer un elevado precio no sólo en el bienestar psicológico de individuos con discapacidad, sino también en la imagen pública y en la aceptación de la discapacidad en la sociedad ${ }^{167}$.

Resulta innegable que potencian el desvalor colectivo de la discapacidad implícito en el aborto embriopático. Suponen que la vida del discapacitado es distinta y de menor valor que las demás de acuerdo con un pronunciamiento oficial de los poderes públicos ${ }^{168}$, por lo que no poder conocer este dato a efectos de un eventual aborto se configura como un daño indemnizable. De hecho, si el nińo finalmente naciera sano y sin discapacidad alguna (porque el «falso negativo» no era tal, sino que era un "verdadero negativo»), no habría responsabilidad por wrongful birth. Estos mensajes se extienden por supuesto a las familias con hijos discapacitados, a las que se proyecta una especie de «culpa moral» por haberlos dejado nacer ${ }^{169}$, dado además con frecuencia el gasto público que generan. Desde la perspectiva del modelo social de la discapacidad, antes mencionado, este tipo de responsabilidad perpetúa estándares sociales de inferioridad, lesivos para la dignidad de esas personas ${ }^{170}$. Además,

167 Hensel (2005: 144), traducción del autor. De hecho, esta autora piensa que el coste de este tipo de acciones es «demasiado alto» y que no deberían admitirse (id.).

${ }^{168}$ Hensel (2005: 173): «Las acciones de wrongful birth y wrongful life conllevan un pronunciamiento de la comunidad, a través de una institución pública, de que la vida de un individuo con discapacidad es peor que la no existencia o que una persona razonable habría abortado a un niño que ahora vive», traducción del autor.

169 Hensel (2005: 177).

170 "Los escritos de las personas discapacitadas confirman que "estas tecnologías nos hacen sentir devaluados como seres humanos" y que muchos de hecho reciben el mensaje de 
puede llegar a contribuir a que la sociedad se inhiba de la atención a los discapacitados con patologías congénitas, relegando de cuestión social a cuestión estrictamente individual y familiar: si nació es porque su madre optó por no interrumpir el embarazo, con lo que ella ha de cargar con los costes, sin que pueda implicar a la sociedad en su conjunto ${ }^{171}$. En cualquier caso, se contempla la patología aislada y se califica de "grave anomalía" sin tener en cuenta el medio social, comunitario y familiar de apoyo, absolutamente clave para la vida de muchos discapacitados.

Además, desde un punto de vista individual han de aplicarse las reglas sobre no discriminación ${ }^{172}$. Como se ha expuesto anteriormente, el hijo que fundamenta la pretensión indemnizatoria de los padres era deseado por estos, pero sin la discapacidad cuyo diagnóstico se omitió. La afirmación, expresa o tácita, de la madre es que, de haber conocido la patología del nasciturus en su debido momento, habría abortado. Y por no haberlo podido hacer reclama daños y perjuicios.

La conducta hipotética de la madre consiste en un tratamiento distinto respecto del feto fundado únicamente en su condición de discapacitado. De haberse producido, tal conducta habría sido antijurídica, pues habría constituido a las claras una actuación contraria a la igualdad proclamada en la Convención y, por interpretación conforme con ella ${ }^{173}$, en el art. 14 de la Constitución. Y nadie puede pretender que los tribunales le amparen para obtener una indemnización por no haber podido desarrollar una acción contraria al ordenamiento.

Como es sabido, existe toda una rica discusión doctrinal sobre la aplicación «inter privatos» de los derechos fundamentales, que ha sido profusamente estudiada en Alemania bajo la denominación de «Drittwirkung der

que "tu nacimiento fue un error. Tu familia y el mundo estarian mejor si no vivieras",, Hensel (2005: 176), traducción del autor.

171 Hensel (2005: 180).

172 Existe otra perspectiva individual relevante: la acción por wrongful birth puede inferir daños psíquicos al discapacitado, si llega a ser consciente de que su madre o sus padres la han ejercitado. En Estados Unidos, en el contexto de hijos no deseados nacidos por wrongful conception se habla de convertir al hijo en un emotional bastard al promover la acción, con las consecuencias que ello puede tener (Hensel, 2005: 154).

173 Conviene recordar a este propósito el art. 10.2 de la Constitución: «Las normas relativas a los derechos fundamentales y a las libertades que la Constitución reconoce se interpretarán de conformidad con la Declaración Universal de Derechos Humanos y los tratados y acuerdos internacionales sobre las mismas materias ratificados por Espańa». 
Grundrechte» ${ }^{174}$. El Tribunal Constitucional se ha hecho eco de ella ${ }^{175}$, pero su exposición excede con mucho los límites del presente trabajo ${ }^{176}$. Aunque a la Constitución no solo están sujetos los poderes públicos sino, como expresa con contundencia su art. 9.1, también los ciudadanos, tal vez hay que distinguir entre unos derechos fundamentales y otros a efectos de su eficacia vertical (frente a las autoridades públicas) u horizontal ${ }^{177}$. Partiendo de que el derecho a la igualdad y no discriminación constituye un verdadero derecho fundamental ${ }^{178}$, el Tribunal Constitucional lo ha aplicado innumerables veces

174 Véase T. de Domingo Pérez (2006), «El problema de la eficacia horizontal de los derechos fundamentales desde una perspectiva histórica», Revista de la Facultad de Ciencias Jurídicas y Sociales de Elche, vol. I, 1, págs. 291-301.

175 Por ejemplo, en la temprana sentencia 18/1984, de 7 de febrero, ponente Rafael Gómez-Ferrer Morant.

176 Uno de los primeros trabajos en derecho español fue el de J. M. Pabón de Acuña (1983), «La llamada 'Drittwirkung' de los derechos fundamentales», en la obra colectiva coordinada por la Dirección General de lo Contencioso del Estado El Poder Judicial, vol. III, Madrid: Instituto de Estudios Fiscales, págs. 2205-2235. Véase J. García Torres y A. Jiménez-Blanco (1986), Derechos fundamentales y relaciones entre particulares, Madrid: Cívitas; F. J. Bastida Freijedo, I. Villaverde Menéndez, P. Requejo Rodríguez, M. A. Presno Linera, B. Aláez Corral, e I. Fernández Sarasola (2004), Teoría general de los derechos fundamentales en la Constitución de 1978, Madrid: Tecnos (págs. 189-195); A. Rodríguez Liboreiro (2007), "Spain: A Jurisdiction Recognizing the Direct Horizontal Application of Human Rights», en D. Oliver y J. Fedtke (eds.), Human Rights and the Private Sphere. A Comparative Study, London-New York: Routledge-Cavendish, págs. 378-398; I. Vivas Tesón (2008), «La horizontalidad de los derechos fundamentales", Bienes de la personalidad. XIII Jornadas de la Asociación de Profesores de Derecho Civil, Servicio de Publicaciones de la Universidad de Murcia, págs. 205-213; T. de Domingo (2011), «La Drittwirkung de los derechos fundamentales: una alternativa al conflictivismo», en A.-L. Martínez-Pujalte y T. de Domingo, Los derechos fundamentales en el sistema constitucional, Granada: Comares, págs. 107138; Díez-Picazo Giménez (2013: 140-146).

177 Obviamente, hay derechos fundamentales que solo tienen sentido frente a las autoridades públicas (v.gr., participación en los asuntos públicos) y otros cuyo campo «inter privatos» es más amplio (v.gr., sindicación o huelga de los trabajadores).

178 No en vano se incluye en el capítulo segundo ("Derechos y libertades») del título I de la Constitución y como tal se le da la máxima protección (arts. 53.2 y 161.1.b de la Constitución). Como destacan Suárez Pertierra y Amérigo, "la consideración del derecho a la igualdad como derecho fundamental ha venido generando una larga polémica» (G. Suárez Pertierra y F. Amérigo (1997), Comentario al art. 14 de la Constitución, en O. Alzaga Villaamil, Comentarios a la Constitución española de 1978, t. II, Madrid: Edersa, págs. 251-266 (pág. 257). Sin embargo, comparto plenamente 
en relaciones jurídicas entre particulares, por ejemplo en el campo de las relaciones laborales ${ }^{179}$.

Pero, incluso si se negara la aplicabilidad del art. 14 de la Constitución en las decisiones que adopten las mujeres sobre la interrupción de su embarazo, no ofrece duda que la admisión de las acciones por wrongful birth implican a los poderes del Estado: al legislativo ${ }^{180}$, que prevé un régimen especial para este tipo de abortos, y al judicial, que asumiendo afirmaciones de conductas discriminatorias concede indemnizaciones a quienes sostienen que las habrían desarrollado, por no haberlo podido hacer. Los poderes públicos están de este modo amparando conductas en claro contraste con los derechos proclamados en la Convención sobre los Derechos de las Personas con Discapacidad.

La posibilidad de que la Convención pueda conducir a cambios en el régimen de responsabilidad por wrongful birth no debe llevar a olvidar, desde luego, la necesidad de evitar prácticas sanitarias contrarias a la lex artis. Sin embargo, es dudoso que el mecanismo de la responsabilidad extracontractual mejore de hecho la calidad de la atención sanitaria. Hay voces que

la opinión de estos autores sobre el carácter de derecho fundamental de la igualdad, tal y como expresan (pág. 258):

«[...] el hecho de que la igualdad se postule generalmente conectada a otros derechos, dándole carácter adjetivo respecto de ellos, no impide su consideración como derecho fundamental $[\ldots]$. Se puede defender, por tanto, [...] que la Constitución española no vincula o supedita el ejercicio del derecho a la igualdad, enunciado en el art. 14, a su relación con otros derechos fundamentales. Es decir, estamos ante un derecho a ser tratado de forma igual, objeto de protección en los mismos términos que los restantes derechos fundamentales, no por asimilación al régimen jurídico de éstos, sino por plena identificación en cuanto a su naturaleza. A esta consideración de la igualdad como derecho fundamental ha venido a sumarse abundante jurisprudencia de nuestro Tribunal Constitucional».

${ }^{179}$ Entre cientos de ejemplos cabe citar la reciente sentencia del Tribunal Constitucional 2/2017, de 16 de enero, ponente Antonio Narváez Rodríguez, en un caso de discriminación laboral por razón de sexo.

180 No obstante, en pura teoría cabrían acciones por wrongful birth que no conllevaran la aplicación de los preceptos legales especiales para discapacitados, en el caso de que la información sobre la patología del feto se hubiera debido obtener dentro de las primeras catorce semanas, en las cuales no es preciso aducir motivo alguno para el aborto. Entonces la demandante podría interponer su acción incluso si no existieran tales preceptos legales. Aunque en la práctica resulta infrecuente un diagnóstico tan temprano, también se trataría de una conducta discriminatoria por motivo de discapacidad que no debería ser tutelada por el Estado. 
lo niegan ${ }^{181}$. La llamada «medicina defensiva» o la proliferación del aseguramiento de la responsabilidad civil son elementos relevantes en este debate. En cualquier caso, la responsabilidad extracontractual no es el único sistema para evitar malas prácticas médicas. Además de la incidencia que podría tener en la carrera profesional del médico o del profesional sanitario en general, el régimen de disciplina colegial ${ }^{182}$, el régimen sancionador de los funcionarios públicos ${ }^{183} \mathrm{o}$, en casos más graves, el Código Penal, pueden ser disuasorios de tales prácticas.

181 T. A. Brennan, C. M. Sox y H. R. Burstin (1996), «Relation between Negligent Adverse Events and the Outcomes of Medical-Malpractice Litigation», The New England Journal of Medicine, 335, págs. 1963-1967; A. R. Localio, A. G. Lawthers, T. A. Brennan et al. (1991), «Relation between Malpractice Claims and Adverse Events Due to Negligence - Results of the Harvard Medical Practice Study III», The New England Journal of Medicine, 325, págs. 245-251. En materia de responsabilidad patrimonial de la Administración mucho se discute sobre la acción de regreso contra el funcionario o empleado público causante del daño, hoy en día regulado en el art. 36.2 de la Ley 40/2015, de 1 de octubre, de Régimen Jurídico del Sector Público. Pese al texto de la norma («exigirá») no resulta muy frecuente, por razones explicables. Véase G. Doménech Pascual (2009), «¿Deberían las autoridades y los empleados públicos responder civilmente por los daños causados en el ejercicio de sus cargos?», Revista de Administración Pública, 180, págs. 103-159; J. L. Martínez-Cardós Ruiz (2005), Temas de responsabilidad, Madrid: Escuela de Práctica Jurídica de la Universidad Complutense (págs. 59-63); J. M. Herrero de Egaña Espinosa de los Monteros (2004), «La responsabilidad patrimonial de las autoridades y del personal al servicio de las Administraciones públicas», Indret Revista para el Análisis del Derecho, 257, págs. 1-24 (págs. 20-22); y también mi libro (2013), Responsabilidad patrimonial de la Administración en materia de seguridad ciudadana, Valencia: Tirant lo Blanch (págs. 51-54).

${ }^{182}$ De acuerdo con los Estatutos Generales de la Organización Médica Colegial y del Consejo General de Colegios Oficiales de Médicos aprobados por Real Decreto 1018/1980, de 19 de mayo (no afectado en esta parte por el Real Decreto 300/2016, de 22 de julio, por el que se aprueban los Estatutos del Consejo General de Colegios Oficiales de Médicos), son faltas disciplinarias "[n]o corresponder a la solicitud de certificación o información en los términos éticos cuando ello no suponga un peligro para el enfermo», «[l] os actos y omisiones que atenten a la moral, decoro, dignidad, prestigio y honorabilidad de la profesión» $\mathrm{y}$ «[1]a desatención maliciosa o intencionada de los enfermos» (art. 64 párrafos 2a), 3b) y 4d)).

183 «El descuido o negligencia en el ejercicio de sus funciones» constituye una falta disciplinaria según el Reglamento de Régimen Disciplinario de los Funcionarios de la Administración del Estado, aprobado por Real Decreto 33/1986, de 10 de enero (art. 8.d). 
Llega el momento de concluir. Tras delimitar el wrongful birth y los elementos de la responsabilidad a él asociados, tal y como se analizan por la jurisprudencia y la doctrina, se ha abordado la incidencia que deba tener la Convención sobre los Derechos de las Personas con Discapacidad, ratificada por España en el año 2007. A su luz se aprecia una discriminación del legislador hacia los discapacitados en el régimen de la interrupción voluntaria del embarazo, que se proyecta sobre la responsabilidad por wrongful birth, tanto civil extracontractual como patrimonial de la Administración. En efecto, esta se construye tutelando el poder judicial conductas abiertamente contrarias al principio de igualdad y no discriminación por razón de la discapacidad y en claro contraste con el espíritu y la finalidad de la Convención. Solo cabe confiar en que la sensibilidad de la sociedad y de los aplicadores del derecho conduzca a una rectificación en este campo. 